\title{
Investigations of a Cretaceous limestone with spectral induced polarization and scanning electron microscopy
}

\author{
Sara Johansson, ${ }^{1}$ Charlotte Sparrenbom, ${ }^{2}$ Gianluca Fiandaca, ${ }^{3}$ Anders Lindskog, ${ }^{2}$ \\ Per-Ivar Olsson, ${ }^{1}$ Torleif Dahlin ${ }^{1}$ and Håkan Rosqvist ${ }^{4}$ \\ ${ }^{1}$ Division of Engineering Geology, Lund University, P.O. Box 118, SE-22100 Lund, Sweden.E-mail: sara.johansson@tg.lth.se \\ ${ }^{2}$ Department of Geology, Lund University, Sölvegatan 12, SE-22362 Lund, Sweden \\ ${ }^{3}$ Department of Geoscience, Aarhus University, C.F. Møllers Allé 4, DK-8000, Aarhus C, Denmark \\ ${ }^{4}$ Tyréns AB, Isbergs gata 15, SE-21119 Malmö, Sweden
}

Accepted 2016 November 14. Received 2016 October 24; in original form 2016 January 27

\begin{abstract}
SUMMAR Y
Characterization of varying bedrock properties is a common need in various contexts, ranging from large infrastructure pre-investigations to environmental protection. A direct current resistivity and time domain induced polarization (IP) survey aiming to characterize properties of a Cretaceous limestone was carried out in the Kristianstad basin, Sweden. The time domain IP data was processed with a recently developed method in order to suppress noise from the challenging urban setting in the survey area. The processing also enabled extraction of early decay times resulting in broader spectra of the time decays and inversion for Cole-Cole parameters. The aims of this study is to investigate if large-scale geoelectrical variations as well as small-scale structural and compositional variations exist within the Kristianstad limestone, and to evaluate the usefulness of Cole-Cole inverted IP data in early time ranges for bedrock characterization. The inverted sections showed variations within the limestone that could be caused by variations in texture and composition. Samples from a deep drilling in the Kristianstad basin were investigated with scanning electron microscopy and energy dispersive $\mathrm{X}$-ray spectroscopy, and the results showed that varying amounts of pyrite, glauconite and clay matrix were present at different levels in the limestone. The local high IP anomalies in the limestone could be caused by these minerals otherwise the IP responses were generally weak. There were also differences in the texture of the limestone at different levels, governed by fossil shapes and composition, proportions of calcareous cement and matrix as well as amount of silicate grains. Textural variations may have implications on the variation in Cole-Cole relaxation time and frequency factor. However, more research is needed in order to directly connect microgeometrical properties in limestone to spectral IP responses. The results from this study show that it is possible to recover useable spectral information from early decay times. We also show that under certain conditions (e.g. relatively short relaxation times in the subsurface), it is possible to extract spectral information from time domain IP data measured with on-off times as short as $1 \mathrm{~s}$.
\end{abstract}

Key words: Tomography; Electrical properties; Geomorphology; Microstructures.

\section{INTRODUCTION}

Characterization of varying bedrock properties is a common need in various contexts, ranging from large subsurface infrastructure investigations to various concerns regarding environmental protection. Rock quality estimations and mapping of the bedrock topography are examples of important geotechnical considerations, while porosity, bedrock fracturing, permeability and groundwater salinity are some of the parameters needed for groundwater modelling and hydrogeological analyses.
Due to the sensitivity of the electrical resistivity method to variations in groundwater content (see e.g. Ward 1990), the method has proven to be a useful tool to map variations in bedrock properties such as fracture zones (e.g. Cavinato et al. 2006; Ganerød et al. 2006; Danielsen \& Dahlin 2009). Additional information on materials or structures in the bedrock, which might not display a variation in resistivity, can be obtained by measurements of induced polarization (IP). In contrast to resistivity, IP is sensitive to microgeometrical surface properties and to certain kinds of minerals (e.g. Slater \& Lesmes 2002a; Kemna 


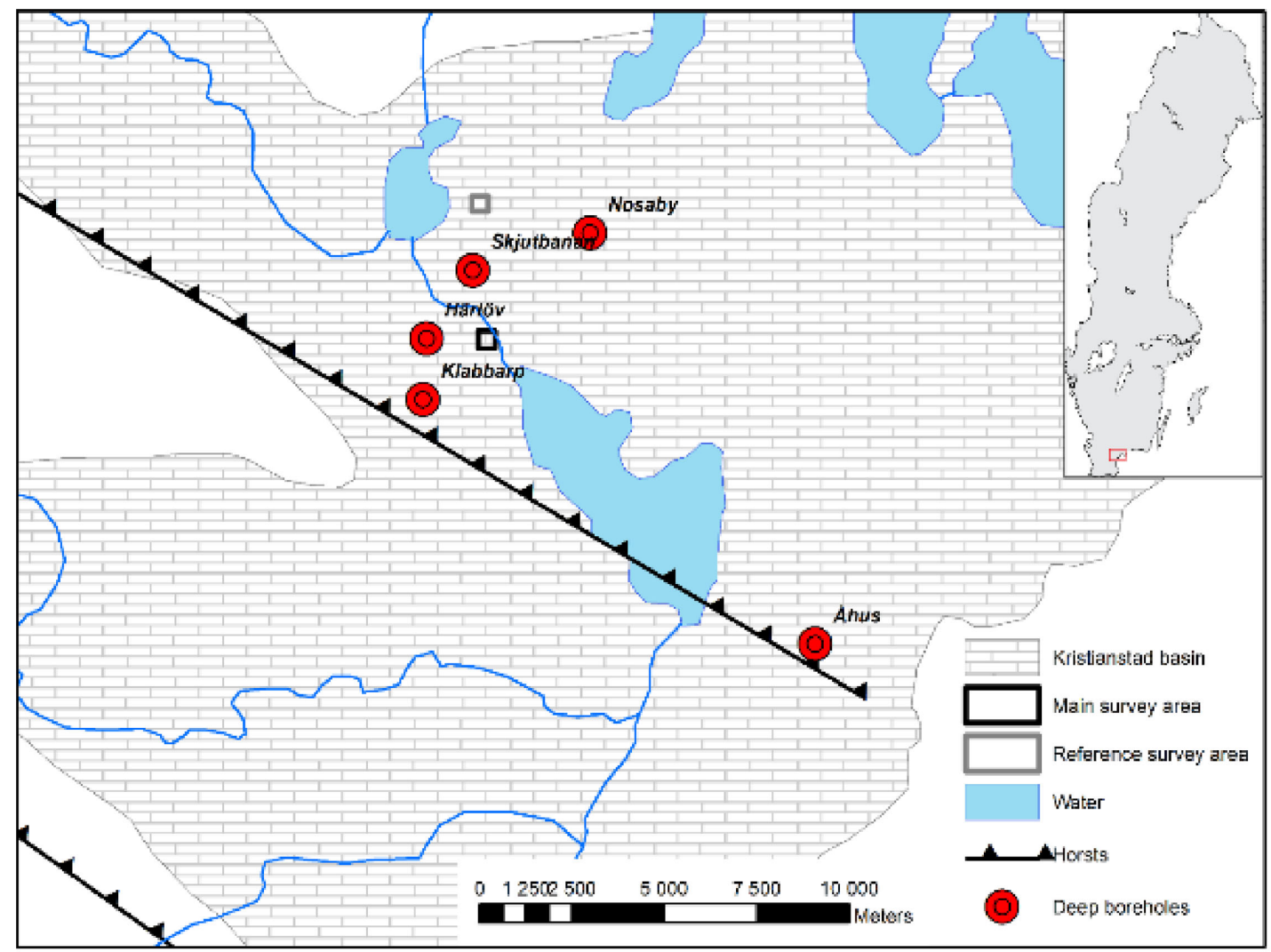

Figure 1. Map of the Kristianstad basin with distribution of limestone and horsts according to Christensen (1984). The locations of the main and reference survey areas are drawn in the map together with the deep drilled borehole reference data available in literature (Kornfält et al. 1978) and accessed from the Åhus drilling.

et al. 2012) and the measurements can in a convenient way be performed simultaneously. For example, earlier surveys on crystalline bedrock and sandstones have shown that anomalies of low resistivity and high IP effects can correspond to clay weathered fracture zones (Marescot et al. 2008; Magnusson et al. 2010).

A direct current resistivity and time domain induced polarization (DCIP) survey aiming to characterize bedrock properties was carried out in the vicinity of a highly contaminated site in Kristianstad, southern Sweden (hereafter referred to as the main survey area). Within the main survey area there is a property contaminated with a plume of free-phase tetrachloroethylene, which has previously been investigated with DCIP by Johansson et al. (2015). However, concerns about groundwater disposal of dissolved contaminants to the surroundings remain. The survey area is situated upon a regional depression in the Precambrian gneiss and granite bedrock, where glauconitic sandstone and limestone have been deposited during the Cretaceous period. In the limestone bedrock, preferential paths for groundwater transport may be due to fractures, karst formation or porosity variations caused by differences in the genesis of the limestone (e.g. Tucker \& Wright 1990).

Limestone formations have been investigated with the resistivity method in previous research. For example, Jurassic limestones and dolomites deposited in a Mesozoic marine basin in France were investigated by Gélis et al. (2010), while Cavinato et al. (2006) investigated Jurassic limestones and Triassic marls in the Italian Maritime Alps. However, IP variations in limestones have not been frequently investigated in previous research.
The time domain IP data measured in the current survey were processed with a novel approach presented by Olsson et al. (2016), which enabled early IP decay times to be recovered. In this way, the spectral range of the time decays increased despite the short acquisition times that had been used during the field acquisition, and the data could be inverted for spectral Cole-Cole parameters (Fiandaca et al. 2012, 2013; Auken et al. 2014). The inverted sections showed Cole-Cole variations within the limestone. Since little is known about spectral IP responses and mechanisms in different kinds of limestones, it is of interest to examine probable sources of the variations observed within the limestone bedrock in this survey.

It is well known that spectral IP mechanisms arise at the grain or pore scale in geological materials (see e.g. Slater \& Lesmes 2002a; Kemna et al. 2012). However, most petrophysical relationships between spectral IP and rock properties have been derived using parameters describing the microgeometry of sandstones, for example pore throat distribution and dominant pore throat size (see e.g. Scott \& Barker 2003; Binley et al. 2005). Since the microstructure of limestones differs from sandstones, a microscale investigation of samples from the Kristianstad limestone was performed in order to give an insight into the microstructure and composition of the investigated rock type.

The main aim of the current study is to investigate if large-scale geoelectrical variations as well as small-scale structural and compositional variations exist within the Kristianstad limestone. The latter is a central part of this paper since small-scale lithological variations could provide plausible explanations to why variations 


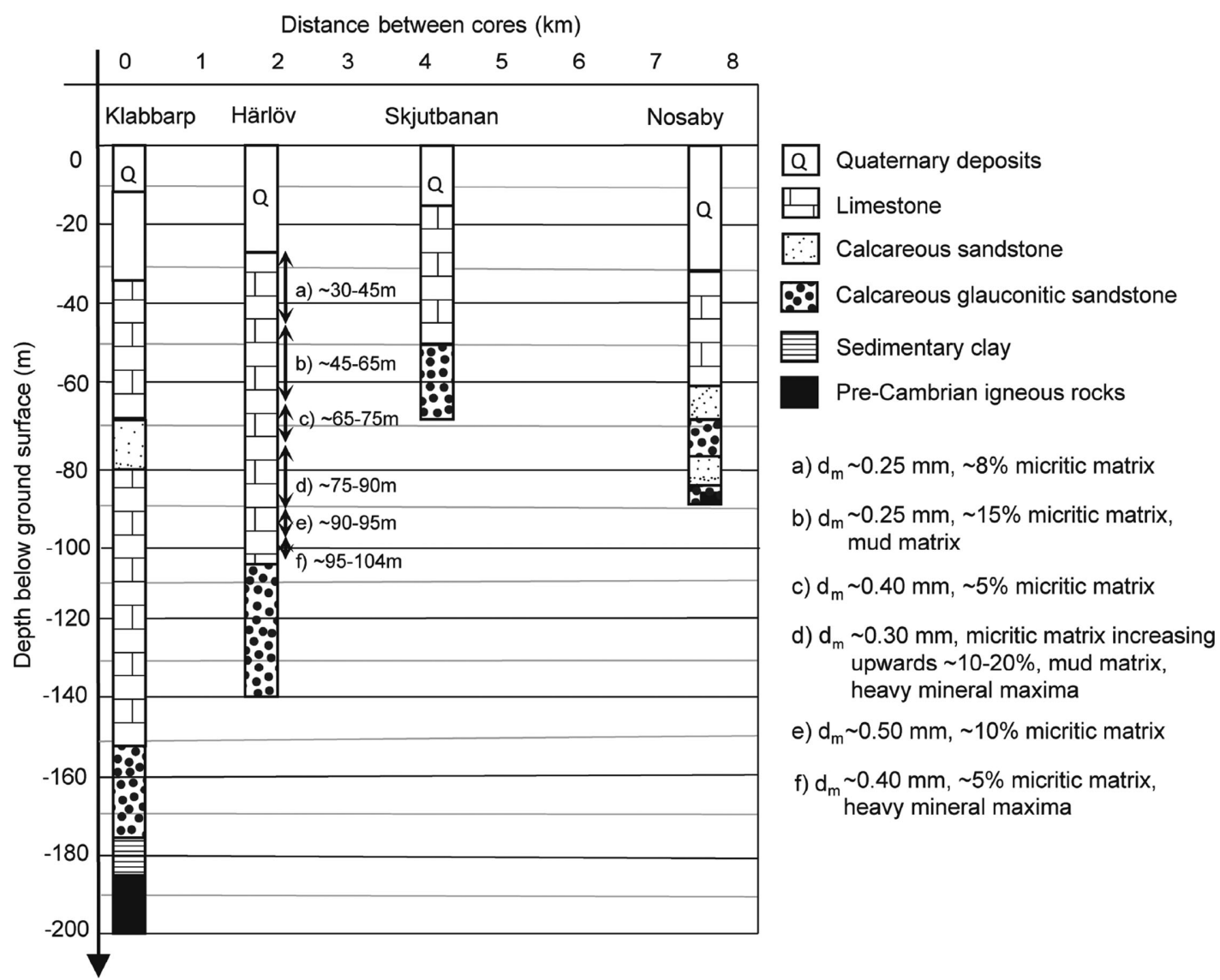

Figure 2. Visualization of the main geological units in the reference cores shown in Fig. 1 (modified from Kornfält et al. 1978).

in Cole-Cole parameters were observed in this study. Empirically established relationships between microstructure and Cole-Cole parameters in limestones are however outside the scope of this paper.

Another aim is to evaluate the usefulness of Cole-Cole inverted IP data in early time ranges for bedrock characterization. The results presented can enhance the planning of future similar DCIP investigations as well as the interpretation of spectral IP data from similar geological environments.

\section{METHODS AND MATERIALS}

\section{Regional geology}

The investigated site is situated in the northeastern part of the province Skåne in southern Sweden, where Cretaceous limestone has been deposited in a depression within the Precambrian gneiss and granite bedrock. The depression, referred to as the Kristianstad basin (Fig. 1), was formed by weathering and kaolinization in the Jurassic period and is bounded towards the southwest by horst structures. The weathering led to a highly uneven topography of the Precambrian bedrock, which can be found at depths down to around 300 m (Kornfält et al. 1978; Christensen 1984).

A poorly lithified and often glauconite rich sandstone rests upon the Precambrian bedrock. The glauconitic sandstone has been formed in a marine environment with relatively high water levels (Kornfält et al. 1978), and it is overlain by the Cretaceous limestone.
Several transgressions and regressions occurred during the late Cretaceous, and the limestone consists to a large degree of carbonate fossil fragments that were deposited in mainly shallow marine environments. Quaternary deposits are found on top of the Cretaceous limestone. These consist of tills, glacial clay, glacifluvial sand and gravel as well as postglacial sand.

The locations of the DCIP surveys performed in this study are shown in Fig. 1, together with the locations of the deep drillings which have been used as reference data for the interpretation of the DCIP signals in the bedrock. The stratigraphy of the cores located closely to the DCIP main survey area (Klabbarp, Härlöv, Skjutbanan and Nosaby) have been described by the Geological Survey of Sweden (Kornfält et al. 1978). The main geological units in these cores are visualized in Fig. 2, and the varying depths to the different units can be followed between the boreholes. The depth and thickness of the limestone is largest in the core from Klabbarp, which is located close to the horst (see Fig. 1). From here to Skjutbanan, the depth to the glauconitic sandstone decreases from $\sim 155$ to $\sim 50 \mathrm{~m}$. As can be seen in Fig. 1, the main survey area is most closely located to the Härlöv and Skjutbanan sites. The most probable depth to the upper surface of the glauconitic sandstone is therefore, based on the available reference cores, somewhere between 50 and $100 \mathrm{~m}$ in the main survey area.

The limestone formation is generally described as made up of relatively well consolidated limestone, loose calcareous sandstone or mixes thereof. The proportion of calcium carbonate is estimated to around 70-80 per cent and consists of sand-sized or finer shelland skeletal particles. Chert and flint are generally not common, 


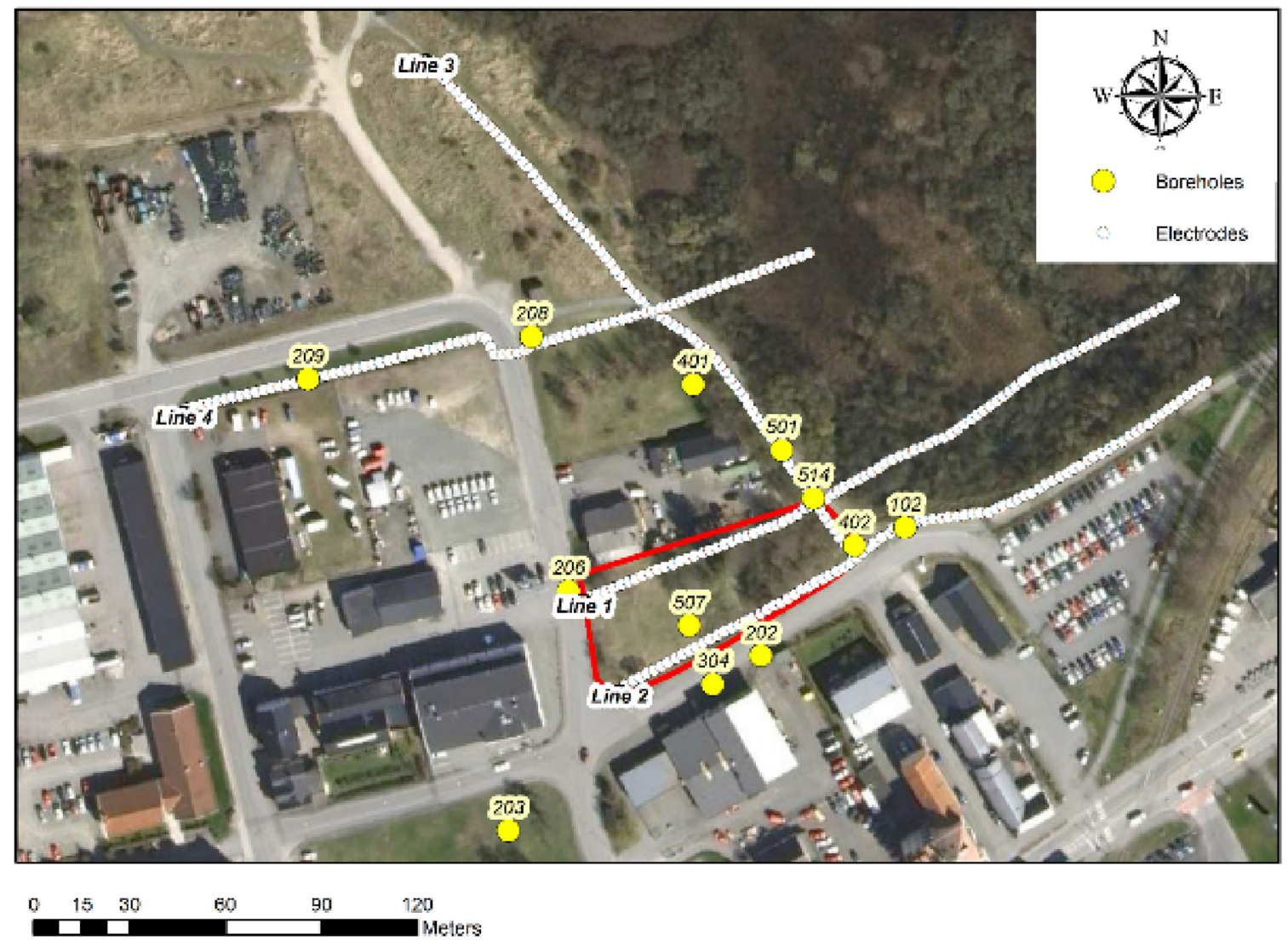

Figure 3. Satellite image showing the investigated surroundings of the contaminated property, which is situated between Line 1 and Line 2 (red area).

but have been observed at depths of 16-40 m beneath Kristianstad. In addition, layers of glauconitic sand are also present at different levels in the limestone (Kornfält et al. 1978). For the Härlöv core, a detailed lithological analysis of the limestone has been carried out (Kornfält et al. 1978). Generalized variations of the mean grain diameter, amount of micritic matrix, mud matrix and heavy minerals within the limestone are reported in Fig. 2.

\section{DCIP survey}

A satellite image of the main survey area is shown in Fig. 3. In an extended area surrounding the contaminated property (red rectangle), data profiles along four 205-m-long 2D DCIP sections were measured (Fig. 3). The aim of the survey was to provide a geological interpretation including possible preferential pathways for contaminated groundwater. The electrode configuration poledipole was used, motivated by the fact that it provides a large depth penetration in combination with a good spatial resolution (Dahlin $\&$ Zhou 2004). A separated cable layout for injecting current and measuring potentials was used in order to reduce capacitive coupling effects. In this layout, one multiconductor cable is used for the current circuit and another for the potential circuit to avoid current leakage between the two (Dahlin \& Leroux 2012). Acid grade stainless steel electrodes were installed with an in-line spacing of $2.5 \mathrm{~m}$ and low electrode contact resistances were assured via Focus One electrode tests (see Ingeman-Nielsen et al. 2016). An ABEM Terrameter LS was used for transmitting current and measuring potentials, and the switching capability of the instrument was in- creased by using the ES10-64 external relay switch. The on- and off-times of the current pulses were $1 \mathrm{~s}$, corresponding to a square wave fundamental frequency of $0.25 \mathrm{~Hz}$. Full waveform data was collected with a sample rate of $1000 \mathrm{~Hz}$.

The boreholes marked with yellow dots in Fig. 3 were drilled down to $10-30 \mathrm{~m}$ below the ground surface prior to the DCIP investigation. The main purpose of the drilling was to determine groundwater contamination levels and the level of the limestone bedrock surface, although the latter was unsuccessful at many locations due to difficult drilling conditions. At locations where it was difficult to determine, the limestone surface was interpreted as significantly weathered. The proposed weathering was assumed to make the upper part of the bedrock less consolidated and therefore more difficult to distinguish from the overlying till.

As can be seen in Fig. 3, the site has an urban character that makes measurements with electrical methods challenging (see e.g. Ward 1990). Power line and train traffic noises at frequencies of 50 and 16 $2 / 3 \mathrm{~Hz}$ were identified in the DCIP raw data. In addition to problems with the noise, urban structures such as buried infrastructure pipes and buildings can lead to anomalies and 3D-effects (see e.g. Dahlin et al. 2007) in the inverted data models. During the interpretation it was therefore important to be able to separate urban from geological sources of the anomalies. The locations of known buried pipes and cables were compared with the DCIP results in order to identify anomalies caused by urban structures. Since buildings, parking lots and roads were occasionally located close to the measurement lines (see Fig. 3), the DCIP results were also compared to satellite images in order to identify possible $3 \mathrm{D}$-effects in the inverted models. 

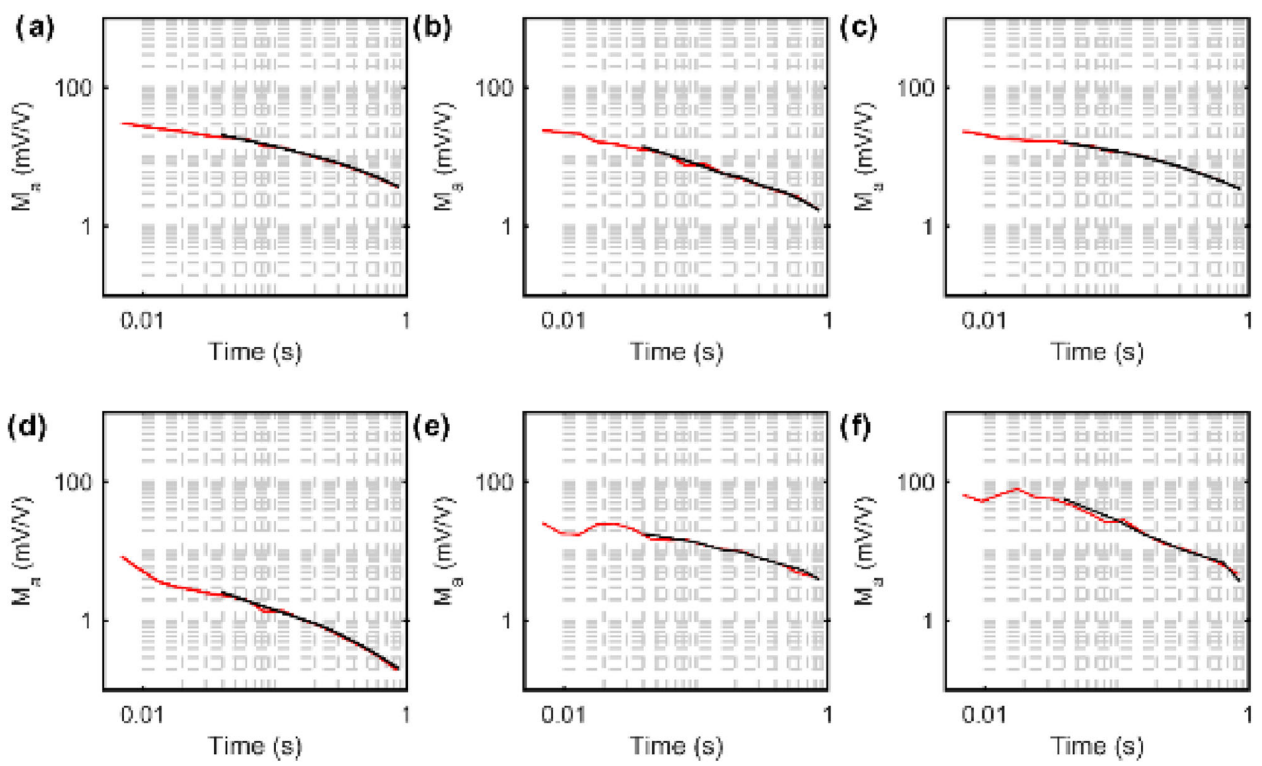

Figure 4. Examples of raw decays extracted with the standard method from the measurement instrument (black lines), compared to the same decays with early time data recovering (red lines) according to Olsson et al. (2016).

Due to the challenging urban setting in the main survey area with buried infrastructure and electromagnetic noise, a reference DCIP profile was also carried out with the same measurement setup and settings. The reference line was located at a distance of approximately $4 \mathrm{~km}$ north of the main survey area (see Fig. 1), in a rural environment that was assumed to be free from both urban noise and groundwater contamination. The lithology can be expected to be similar for both survey areas even though the thicknesses of the different geological units are likely to differ (see Fig. 2).

\section{Data processing and inversion}

Each DCIP measurement profile resulted in 3354 data points containing raw apparent resistivity values and IP decays. IP decays are measured as the decline of potential after the interruption of the injected current pulse. The potential decays are usually gated in logarithmically spaced time windows in which the average potential value is calculated by the instrument software (see e.g. Sumner 1976). In this survey, the chosen IP gates of the acquired data were multiples of $60 \mathrm{~ms}$ in order to suppress the periodic noise from the power line and train traffic frequencies. A drawback of this method is that data from early decay times $(<40 \mathrm{~ms})$ are removed which reduces the spectral range of the IP decays. However, the collection of full-waveform data in this survey enabled the possibility to regate the IP decays after the measurements. A processing scheme recently developed by Olsson et al. (2016) was used to recover data from early times and increase the spectral information content of the IP decays. This processing scheme applies a model based harmonic denoizing for supressing the periodic noise which reduces the need for long $(60 \mathrm{~ms})$ gates and makes it is possible to retrieve the decay information from one to two milliseconds after the current pulse. Furthermore, the processing applies a despiking algorithm and an improved estimate of the background drift which can handle also non-linear drift cases such as electrode polarization effects. This improved drift estimate ensures a more accurate recovery of the IP decay shape (and thus spectral IP content) at late times compared to the normally used linear background drift estimate (see Olsson et al. 2016). Data examples of the difference in time ranges obtained before and after the signal processing scheme are visualized in Fig. 4 (black and red lines, respectively). The signal processed IP data resulted in decays discretized with 16 logarithmically separated gates in the time range of $0.006-0.974 \mathrm{~s}$. This time range can be compared to a frequency range of approximately $1-140 \mathrm{~Hz}$, considering the corresponding frequencies $(f)$ of signals with periods $(T)$ equal to the centre gate times $(f=1 / T)$. For many decays, the early time gates seemed to be well retrieved (Figs $4 a-c$ ), while they probably were affected by coupling effects or other noise in others (Figs $4 \mathrm{~d}-\mathrm{f}$ ). The signal processed decay data were therefore further processed in Aarhus Workbench (Auken et al. 2009) prior to the inversions. All time gates or decay curves that seemed affected by coupling effects, measurement errors or periodic/aperiodic noise were removed.

The apparent resistivity values and the full-decay IP data were inverted in 2D in AarhusInv (Auken et al. 2014) following Fiandaca et al. (2013). The inversion is performed iteratively, with an accurate description of the transmitter waveform and receiver transfer function in the forward computations for an unbiased reconstruction of the spectral information contained in the time-domain decay series, in terms of Cole-Cole model. The Cole-Cole model is a commonly used phenomenological model in which the resistivity $\rho(\Omega \mathrm{m})$, the intrinsic chargeability $m_{0}(\mathrm{mV} / \mathrm{V})$, the relaxation time $\tau$ (s) and the frequency factor $c$ (dimensionless) describe the magnitude and shape of the decay curve $V(\mathrm{mV})$ as a function of time $t$ (Pelton et al. 1978):

$V(t)=\frac{I}{k} \rho m_{0} \sum_{n=0}^{\infty} \frac{(-1)^{n}\left(\frac{t}{\tau}\right)^{n c}}{\Gamma(n c+1)}$,

where $I(A)$ and $k(m)$ are the injected current and the geometrical factor of the quadrupolar measurement, respectively. The ColeCole model assumes a sharp drop of the voltage after the current turn off, with the intrinsic chargeability $m_{0}$ being the ratio of voltage immediately after to the voltage immediately before cessation of an infinitely long charging current. The relaxation time $\tau$ determines the length of time required to the decay in time domain 


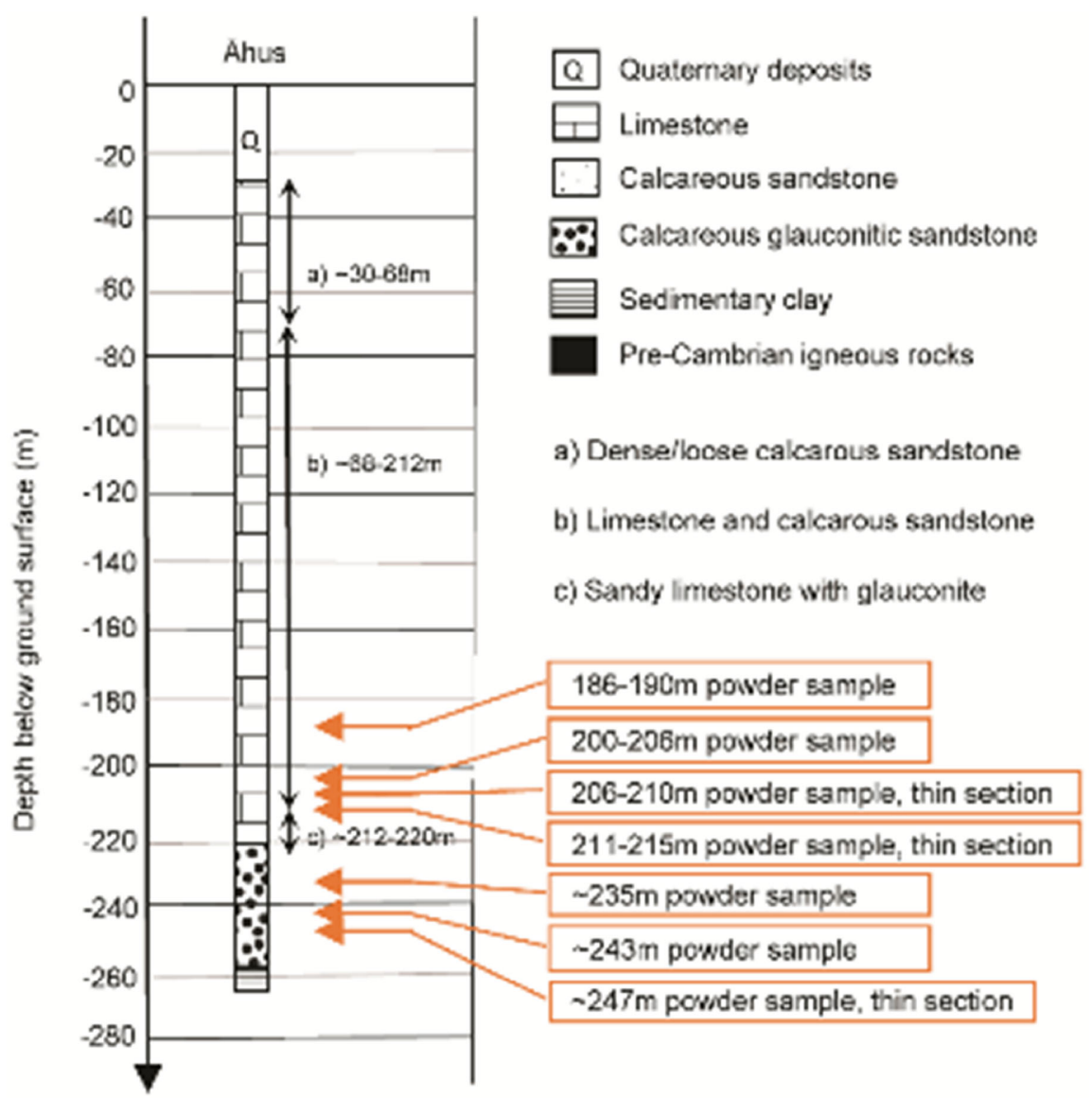

Figure 5. The main geological units in the Åhus core (personal communication, Martin Ekvy, Malmberg Borrning, June 2015). The levels where samples were collected and analysed with SEM and EDS are shown.

and is generally considered to be proportional to the square of the characteristic length scale over which the charges polarize (Slater \& Lesmes 2002a). The characteristic length scale is dependent on microgeometrical characteristics, for example the main grain or pore size in the material (e.g. Scott \& Barker 2003, Binley et al. 2005). A wider distribution of length scales generally leads to a lower frequency factor (and a less pronounced drop in the polarization at the relaxation time).

In all the inversions a homogeneous starting model was used and the stopping criterion for the inversion was a relative change in the objective function below 2 per cent. Vertical constraints, equal to 1.5 , and lateral constraints, equal to 1.15 , were set between the ColeCole parameters of adjacent cells. These constraint values allow roughly 50 per cent of vertical variation and 15 per cent of horizontal variation between the constrained parameters (Fiandaca et al. 2013). The data standard deviation used in the inversion were computed summing a uniform standard deviation (equal to 2 per cent for resistivity and 10 per cent for chargeability) to a voltage dependent noise (Gazoty et al. 2013) that better describes the effect of the signal level on the data uncertainty. The voltage dependent noise model was controlled by a voltage noise threshold $V_{\text {noise }}=1.0 \mathrm{mV}$, for a nominal integration time of $10 \mathrm{~ms}$ (Olsson et al. 2015).

The Cole-Cole inversion of a measurement profile results in four sections showing the distributions of the Cole-Cole IP parameters $\rho, m_{0}, \tau$ and $c$ in the subsurface. In each section the depth of investigation (DOI), computed following Fiandaca et al. (2015), is shown by shading the areas below the DOI. The DOI computation is based on an approximated covariance analysis applied to the model output from the inversion while considering the data standard deviations. Furthermore, the cross-correlations between intrinsic parameters are taken into account in the computations, which is crucial when strong cross-correlations are expected. Below the DOI the vertical and horizontal parameter variations are affected by the constraints or equivalences between different Cole-Cole parameters, while above the DOI the variations are primarily data driven.

The strength of the $m_{0}$ signals are dependent on both capacitive and conductive properties of the subsurface materials. Normalized chargeability is often more effective to use in order to visualize surface polarization properties, since this parameter is normalized against the ground conductivity (Slater \& Lesmes 2002b). Therefore, the section of normalized chargeability $m_{0} \sigma$ (calculated by dividing the Cole-Cole chargeability $m_{0}$ with the resistivity $\rho$ ) is also presented in the inversion results, together with the DC and IP data misfits computed along the profile. The misfit is expressed in terms of the $\chi$ value defined as:

$\chi=\sqrt{\frac{\sum_{i=1}^{N} \frac{\left(d_{i}-f_{i}\right)^{2}}{\sigma_{i}{ }^{2}}}{N}}$,

where $d_{i}$ is the $i$ th datum with standard deviation $\sigma_{i}, f_{i}$ is the corresponding forward response and $N$ represents the number of data. 

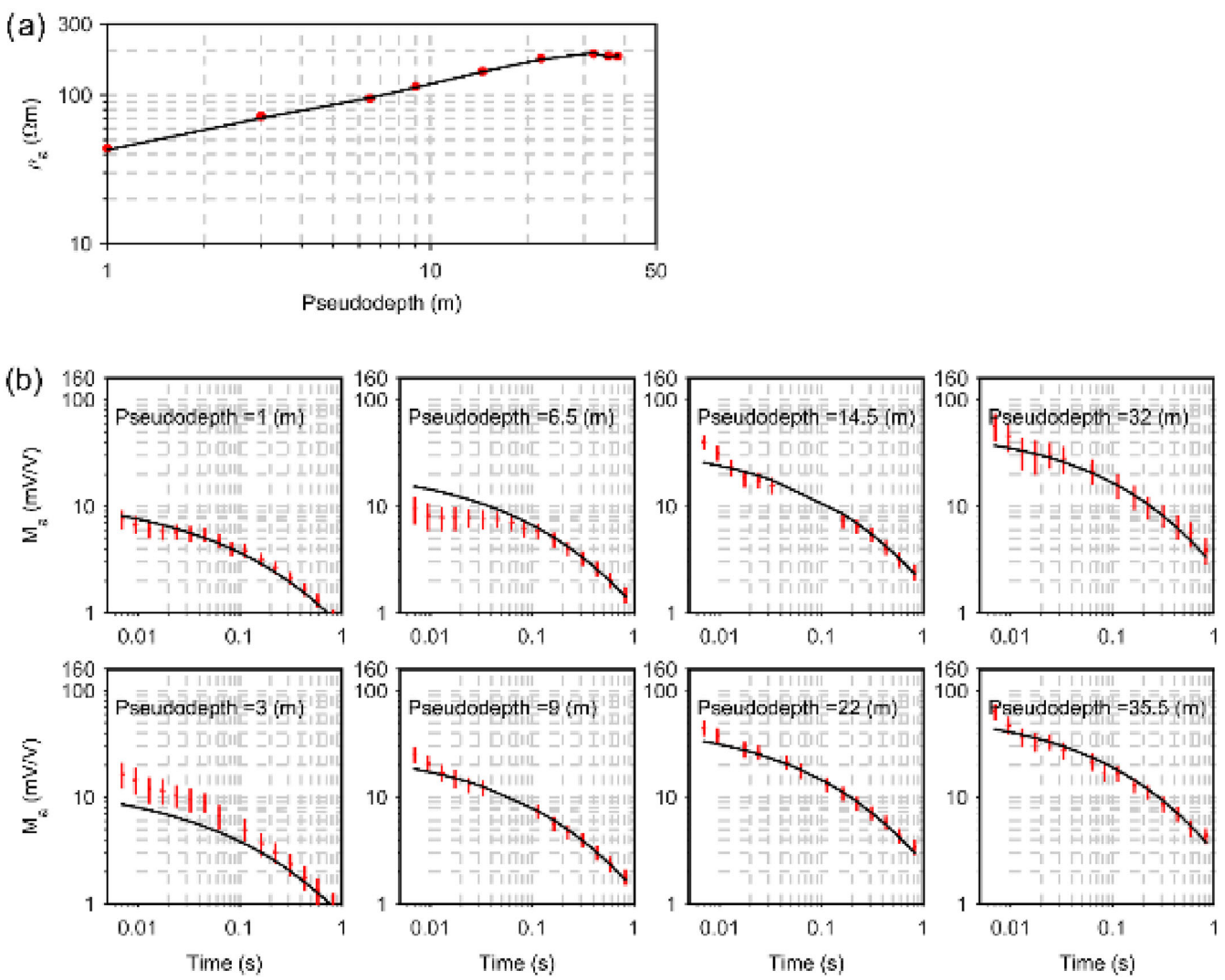

Figure 6. Graphical examples of data and model fit for (a) resistivity data and (b) IP decay curves.

\section{SEM and EDS analysis}

Although no rock cores are available from the field site, lithological descriptions of cores in the vicinity were accessible in literature (Kornfält et al. 1978) and from a drilling in Åhus in the Kristianstad basin (Fig. 1). The latter was carried out by an entrepreneur after the DCIP survey, who permitted access to the lithological description of the borehole as well as samples from different levels (see Fig. 5). The samples consist of drill cuttings collected from seven different levels between 80 and $250 \mathrm{~m}$ depth below the ground surface. The Åhus borehole is located close to the horst in the Kristianstad basin (Fig. 1), where the thickness of the limestone is around $190 \mathrm{~m}$, and the surface of the glauconitic sandstone is located around $220 \mathrm{~m}$ below the ground surface. The samples that were analysed with SEM and EDS represent the transition between the deeper part of the limestone and the glauconitic sandstone. It was assumed that similar properties could be found at shallower depths in the main and reference survey areas, since the upper surface of the glauconitic sand likely occurs at 50-100 $\mathrm{m}$ depth at these locations (see Fig. 2).

The drill cutting material was stored in cool conditions before it was oven dried at $105^{\circ} \mathrm{C}$ for $18 \mathrm{hr}$. Samples from all seven borehole levels were gently ground in a mortar and the powders were mounted on glass plates with carbon tape. The samples were coated with a thin layer of carbon in a vacuum evaporator (Cressington Carbon Coater 108 carbon $\mathrm{A}^{-1}$ ) before they were examined with scanning electron microscopy (SEM, Hitachi S-3400N) and energy dispersive X-ray spectroscopy (EDS, Oxford instruments Inca X-sight). The electron source is a tungsten hairpin filament, and the probe current $60.9 \mu \mathrm{A}$ and the acceleration voltage $15 \mathrm{kV}$ were used for the scanning. The main elements in the sample were indicated by an analysis of the spectra collected in selected scan areas. A backscatter electron (BSE) detector was used to scan the samples for high density minerals. The chemical composition of the high density minerals was examined by acquiring spectra in a spot scanning mode (for more information on SEM and EDS-analysis, see Friel 2003 and references therein).

SEM and EDS analyses of powder samples give a qualitative estimate of the mineralogical content in the samples, while thin section analysis enables both structural and quantitative results. Following a review of the grinded powder results, samples from three levels were selected for a more detailed thin section analysis. Dried rock samples were embedded in epoxy resin, and thin sections were made according to the method described in Houssaye et al. (2013). The thin sections were examined at variable magnification in a petrographic microscope (Nikon Eclipse E400 POL) and the carbonate textures of the rock samples were determined according to the widely used Dunham classification system (see Dunham 1962) via point counting ( 300 points). Textures are classified according to the relative proportion of grains in relation to matrix and cement; mudstones and wackestones have a matrix-supported microstructure, whereas grainstones and packstones are grain supported. The different carbonate textures can have implications on rock properties, such as groundwater permeability and porosity (Dunham 1962). Moreover, the relative proportion of grain types in the thin sections were calculated (300 grains per thin section). The thin sections were then coated with a thin layer of carbon and examined in the SEM. A secondary electron (SE) detector was used to obtain images of the samples in a low vacuum mode $(60 \mathrm{~Pa})$. Chemical mapping was made in the spectrum range $0-10 \mathrm{keV}$ with a map resolution of 
Line 1

(a)

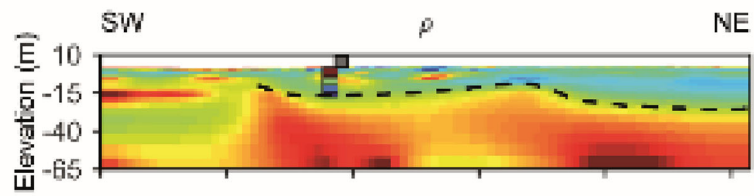

(b)

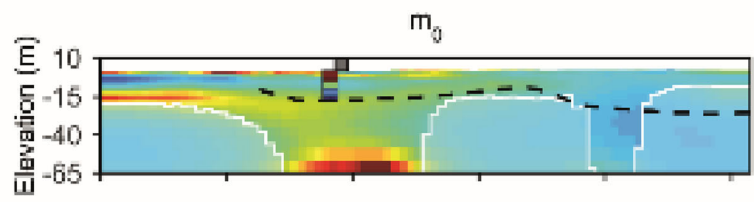

(c)
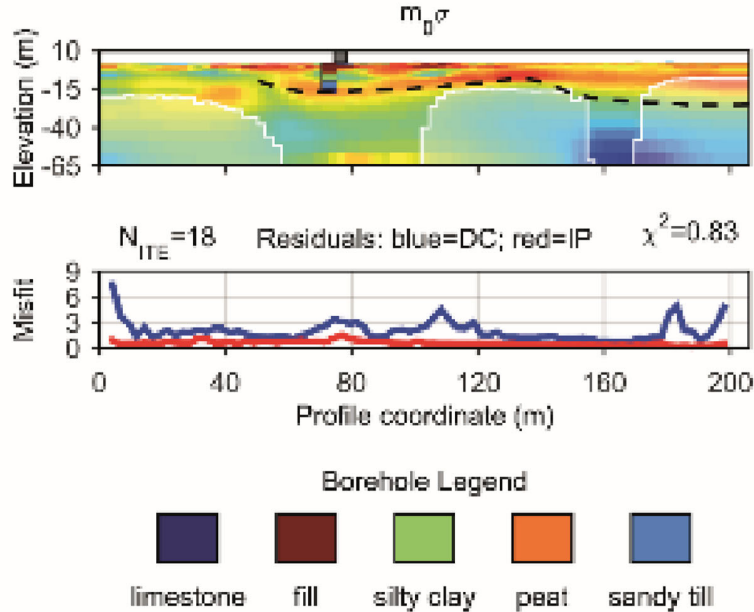

Line 2
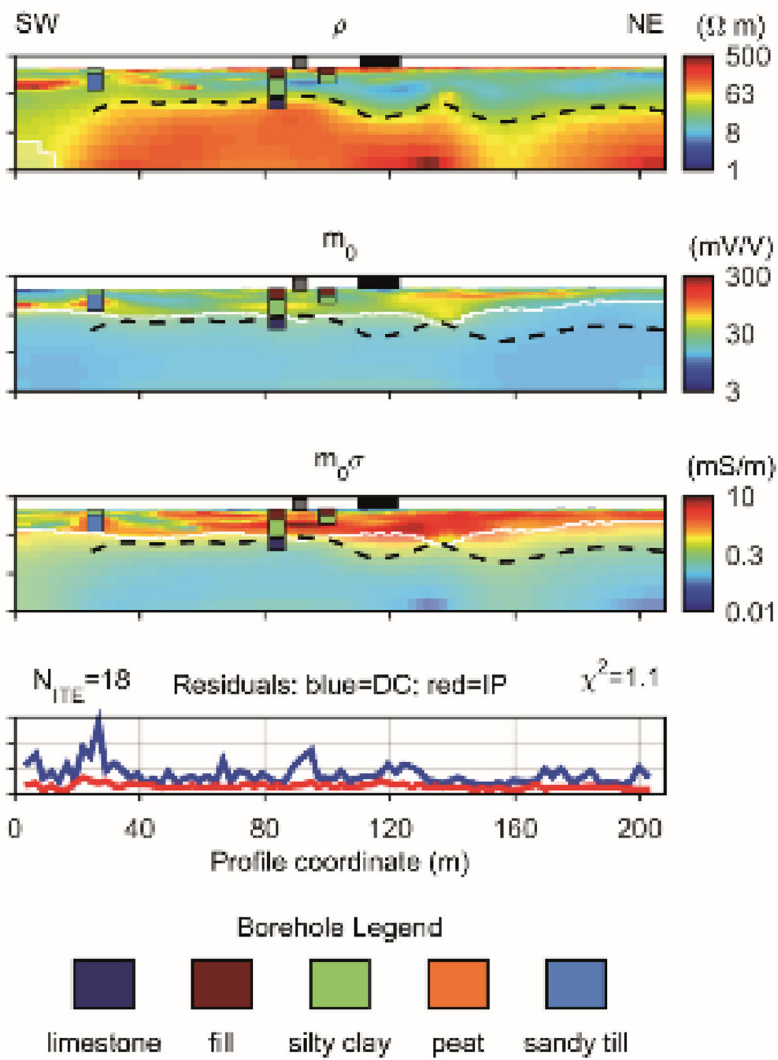

Figure 7. Resistivity, Cole-Cole chargeability and normalized chargeability models of Lines 1 and 2 with reference borehole data (compare with Fig. 3 ) and DOI threshold indicated by white lines. The dashed black lines indicate the interpreted bedrock level. Grey markers show locations were small paths are crossed, while the black markers show where roads with buried pipes or cables are crossed. (a) The bedrock level indicated by the deeper borehole corresponds to transition from low to high resistivity, which is interpreted as the limestone bedrock surface (black dashed line). (b) The chargeability values are generally low in the limestone bedrock, with the exception of a deep anomaly at $\sim 60-100 \mathrm{~m}$ in Line 1 . (c) The normalized chargeability values are low in Line 2 , while they are slightly elevated in the southwestern half of Line 1.

$256 \times 192$ pixels. The exposure time for the individual mappings was around $1500 \mathrm{~s}$.

\section{RESULTS}

\section{DCIP results}

The inversions of all the acquired profiles present a good data fit. A graphical example of resistivity data and model fit is shown in Fig. 6(a), while Fig. 6(b) shows the model fit of the decay curves. The red bars represent the imposed standard deviation on the measured data values while the black lines show the inverted decays.

Inverted DCIP models are shown in Figs 7-9 together with data misfit values and DOI estimations. In the shaded areas below this DOI threshold, the inverted Cole-Cole parameters are more affected by equivalences between different Cole-Cole parameters or constraints, and the uncertainty in the inverted values are therefore higher. However, average parameter values below the DOI can still be indicated by the data.

Fig. 7 shows the inverted resistivity, Cole-Cole chargeability and normalized chargeability results from lines 1 and 2 . These lines run parallel to each other at a distance $20-30 \mathrm{~m}$ and are intersected by line 3 around the distance $75 \mathrm{~m}$ (see Fig. 3). Both lines begin in the urban site $(\sim 0-90 \mathrm{~m})$ and end in the wetland east of the site $(\sim 90$ $200 \mathrm{~m}$ ). The resistivity results show a quite clear transition at a level that is interpreted as the limestone bedrock surface (black dashed line). Two of the boreholes along profiles 1 and 2 reach down into the bedrock, where the transition between sandy Quaternary deposits and the consolidated limestone is in agreement with the transition in resistivity (Fig. 7a).

The unconsolidated materials (mainly silty clay) generally have resistivity values below $50 \Omega \mathrm{m}$. In the northeastern part of the site, they seem to give rise to well defined zones of high normalized chargeability $(\sim 50-200 \mathrm{~m}$ in Fig. $7 \mathrm{c})$. In the southwest $(\sim 0-50 \mathrm{~m})$, the normalized chargeability sections show a more varying pattern and sometimes an unclear transition between the Quatenary deposits (sandy till) and the consolidated limestone.

In the interpreted limestone bedrock below the dashed line, the resistivity values are relatively high (above $100 \Omega \mathrm{m}$ ). The chargeability sections (Fig. 7b) indicate low values with the exception of a deep anomaly at $\sim 60-100 \mathrm{~m}$ in Line 1 . The normalized chargeability sections (Fig. 7c) also indicate low values in Line 2, while they are slightly elevated in the southwestern half of Line 1. It is possible that the chargeability and normalized chargeability values in the southwestern part of Line 1 are influenced by 3D-effects 
Line 3

(a)

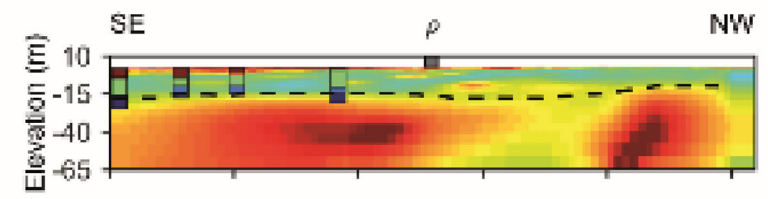

(b)

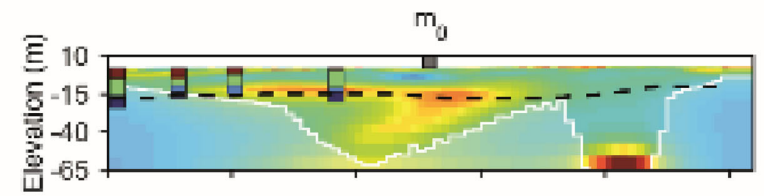

(c)

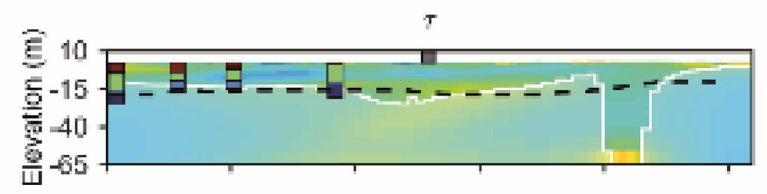

(d)

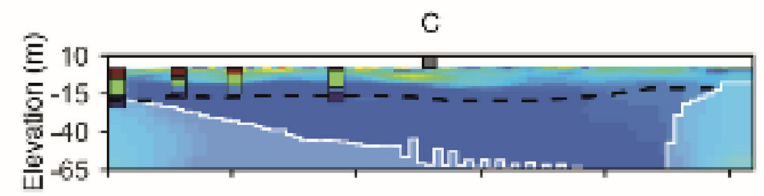

(e)
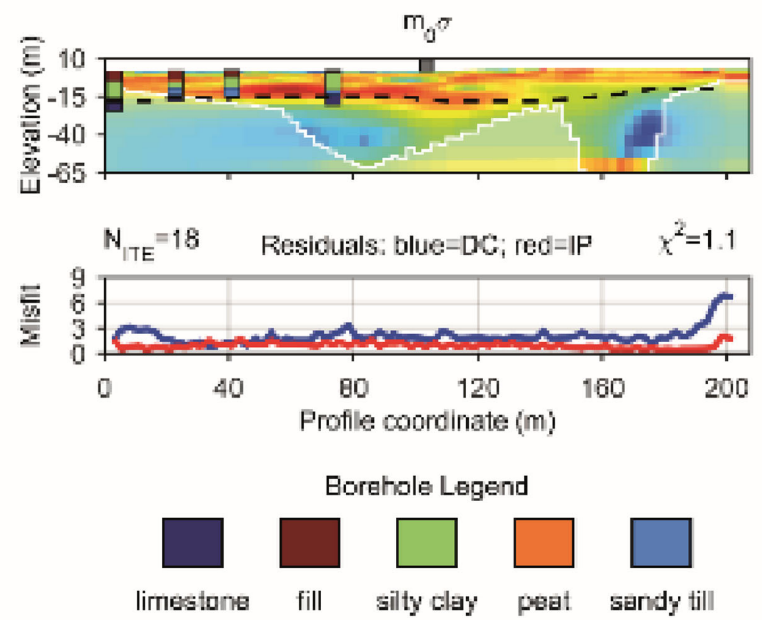

Line 4
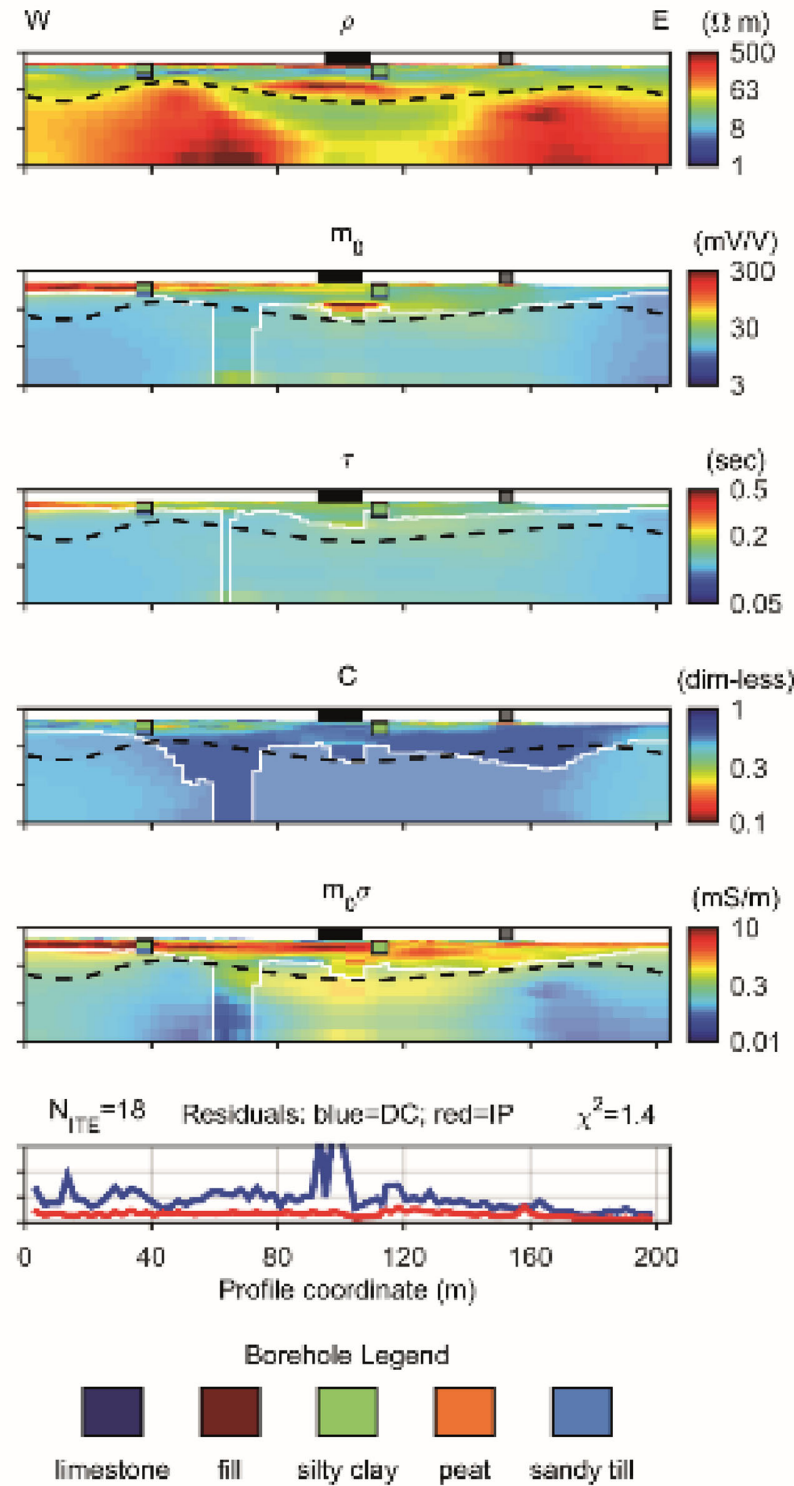

Figure 8. Resistivity, normalized chargeability and Cole-Cole inverted models of Line 3 and Line 4 with reference borehole data and DOI threshold indicated by white lines. The dashed black lines indicate the interpreted bedrock level. Grey markers show locations were small paths are crossed, while the black markers show where roads with buried pipes or cables are crossed. (a) The resistivity models shows lower values in the limestone bedrock at 90-160 m in Line 3 and $80-140 \mathrm{~m}$ in Line 4. (b) The chargeability values are generally low in the limestone bedrock with the exception of anomalies at 80-120 $\mathrm{m}$ and $160-170 \mathrm{~m}$ in Line 3. (c) The relaxation time is generally below $0.2 \mathrm{~s}$ in the bedrock, except at the locations of the chargeability anomalies in Line 3 where it is slightly more elevated compared to the surroundings. (d) The distributions in frequency factor do not indicate a heterogeneous bedrock. (e) The normalized chargeability is elevated in the bedrock at approximately $80-150 \mathrm{~m}$ in both lines.

arising from the building and fence close to the measurement line (see Fig. 3).

Fig. 8 shows the inverted resistivity, Cole-Cole parameters and normalized chargeability sections from lines 3 and 4 . These lines were placed perpendicular to each other and intersect each other at $100 \mathrm{~m}$ in Line 3 and $150 \mathrm{~m}$ in Line 4 (see Fig. 3). Three of the boreholes in Line 3 reaches down into the bedrock, where they match the transition from low to high resistivity (Fig. 8a).

In Line 3, there is a zone of lower resistivity in the bedrock at distance $\sim 115-150 \mathrm{~m}$. The normalized chargeability model (Fig. 8e) also indicate an anomalous zone in the bedrock, which coincides with the low resistivity zone. No obvious sources of urban structures which could explain this zone in the limestone could be identified, as no larger roads with buried pipes or cables were crossed. The environment around the anomaly is also free from buildings (see Fig. 3) which speaks against 3D-effects caused by urban features. A similar pattern was observed in line 4 , where a zone of lower resistivity (Fig. 8a) coincides with elevated normalized chargeability (Fig. 8e) at $\sim 110-150 \mathrm{~m}$. The location of this zone is beneath a larger road where pipes and cables are located at shallow depths, but it is less likely that the anomalous zone is caused by these; a well delineated anomaly which probably corresponds to the effects of the 


\section{Reference Line}

(a)

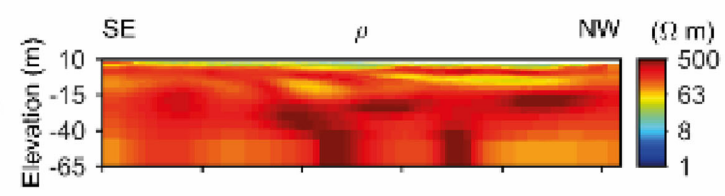

(b)

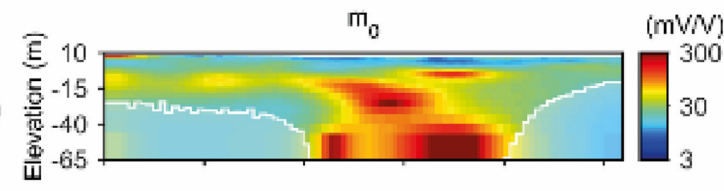

(c)

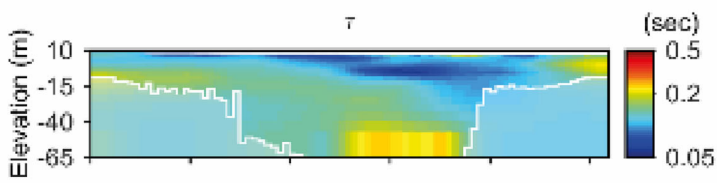

(d)

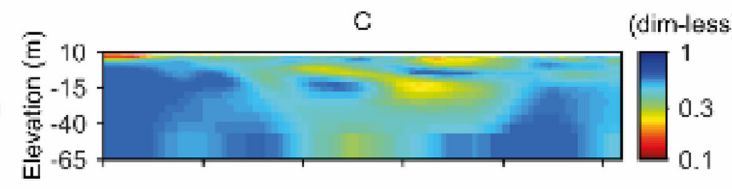

(e)
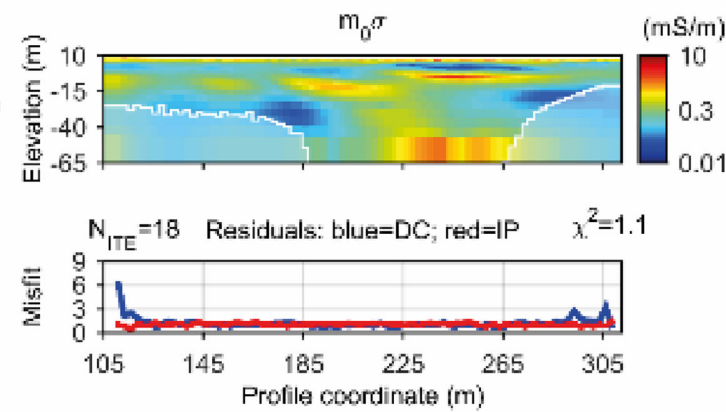

Figure 9. Resistivity, normalized chargeability and Cole-Cole inverted models of the reference line and DOI threshold indicated by white lines. The resistivity model (a) shows high resistivity beneath a shallow low resistive till layer. The chargeability and normalized chargeability values $(b$ and e) are generally low except for a well-defined anomaly. The Cole-Cole relaxation time (c) and frequency factor (d) sections show interesting variations that might reflect textural variations within the limestone.

road and/or pipes is clearly visible in the resistivity and chargeability sections (Figs $8 \mathrm{a}$ and $\mathrm{b}$ ) at $\sim 10 \mathrm{~m}$ depth $(\sim 100-115 \mathrm{~m}$ ),

Two anomalies with higher Cole-Cole chargeability and slightly elevated relaxation time can be observed in the interpreted bedrock in Line 3 (Figs $8 \mathrm{~b}$ and c). One of the anomalies is deeply located $(\sim 160-170 \mathrm{~m})$ while the other can be found at a shallower depth $(\sim 80-120 \mathrm{~m})$. The frequency factor section (Fig. 8d) indicate relatively low values close to the ground surface whereas the parameter is high in the interpreted bedrock.

The Cole-Cole inverted results and normalized chargeability measured in the reference line are shown in Fig. 9. The depth to the limestone bedrock surface seems much shallower compared to the main survey area; only a thin layer of lower resistivity can be found close to the ground surface (Fig. 9a). The resistivity range in the consolidated limestone is of the same order of magnitude as in the main survey area or slightly higher. A major zone of higher Cole-Cole chargeability can be observed at $80-160 \mathrm{~m}$ (Fig. $9 \mathrm{~b}$ ). The zone is also visible in the normalized chargeability section (Fig. 9e), but with weaker values and less pronounced compared to the low chargeability of the surrounding bedrock. The relaxation time and frequency factor sections ( $9 \mathrm{c}$ and $\mathrm{d}$ ) also show interesting patterns that might indicate textural variations within the bedrock. In the reference line, no known man-made constructions or installations are present, which means the variations in IP responses probably can be linked to variations in the limestone composition or structure rather than to urban disturbances.

The resistivity and normalized chargeability sections of the four profiles in the main survey area are visualized in a fence diagram in Fig. 10. Despite the noise problems related to the urban environment, the data in the models are in agreement with each other which confirm a certain degree of confidence in the results.

It can be concluded that the resistivity values of Quaternary deposits are generally below $50 \Omega \mathrm{m}$ in the main survey area. According to the borehole information, the fill, silty clay and peat layers give rise to high normalized chargeability in all profiles. The resistivity in the interpreted limestone bedrock generally varies in the range 100-500 $\Omega \mathrm{m}$. The main low resistivity anomalies with elevated normalized chargeability that were observed in Line 3 and 4 (Fig. 8) seem geometrically connected, as shown in Fig. 10. Despite being inverted in 2D, the inverted profiles match well at the intersection. The anomalous zone might also extend into the southwestern most parts of Lines 1 and 2 (even though the data coverage is low here and the values in the bedrock should be interpreted with care).

\section{Structure and mineral content of drill cutting samples}

Among the seven borehole samples collected from the Åhus borehole, the texture, degree of consolidation and colour varied. Qualitative observations are summarized in Table 1 together with an overview of the results from the SEM and EDS analyses of the grinded powder samples. In addition to $\mathrm{Ca}, \mathrm{Si}, \mathrm{K}, \mathrm{Al}$ and $\mathrm{Mg}$, which were found in varying amounts in most of the samples from all borehole levels in Table 1, traces of metallic elements were also found. Iron was found in most of the samples, often in the form of pyrite but also in other compounds, probably iron oxides. In addition, $\mathrm{Ti}, \mathrm{Cr}, \mathrm{Ni}$ and $\mathrm{W}$ were found in several samples but the possible mineral form of these elements were difficult to determine. It is possible that some of these elements originates from the drilling equipment.

Photographs of the thin section from borehole level 206-210 m are shown in Fig. 11. The material is almost exclusively made up of sand-sized carbonate grains (fossil fragments/skeletal grains, relatively well sorted) and calcite cement. The rock sample in the thin section consists of 55 per cent grains, 34 per cent cement and 11 per cent micritic matrix (Fig. 11a). According to the Dunham classification system (see Dunham 1962), the sample can be described as a grainstone with subordinate packstone. Most grains in the sample are indeterminable abraded/rounded carbonate grains. Still, a variety of fossil types are recognized in the grain assemblage. Small curved shells, likely ostracode valves (see e.g. Adams et al. 1984), are relatively common at this borehole level (Fig. 11b). Other grains include foraminifera, putative coralline algae and phytodebris and fragments of echinoderms (Fig. 11c).

Fig. 12 shows the results of the SEM and EDS-analysis of the thin section subarea shown with a red dashed quadrangle in Fig. 11(a). The SE image show the surface topography of the investigated area, while the relative concentrations of the different elements in the sample $(\mathrm{Ca}, \mathrm{Si}$ and $\mathrm{S})$ are related to the intensity of the colours (different colours are used for visualizing different elements). The 


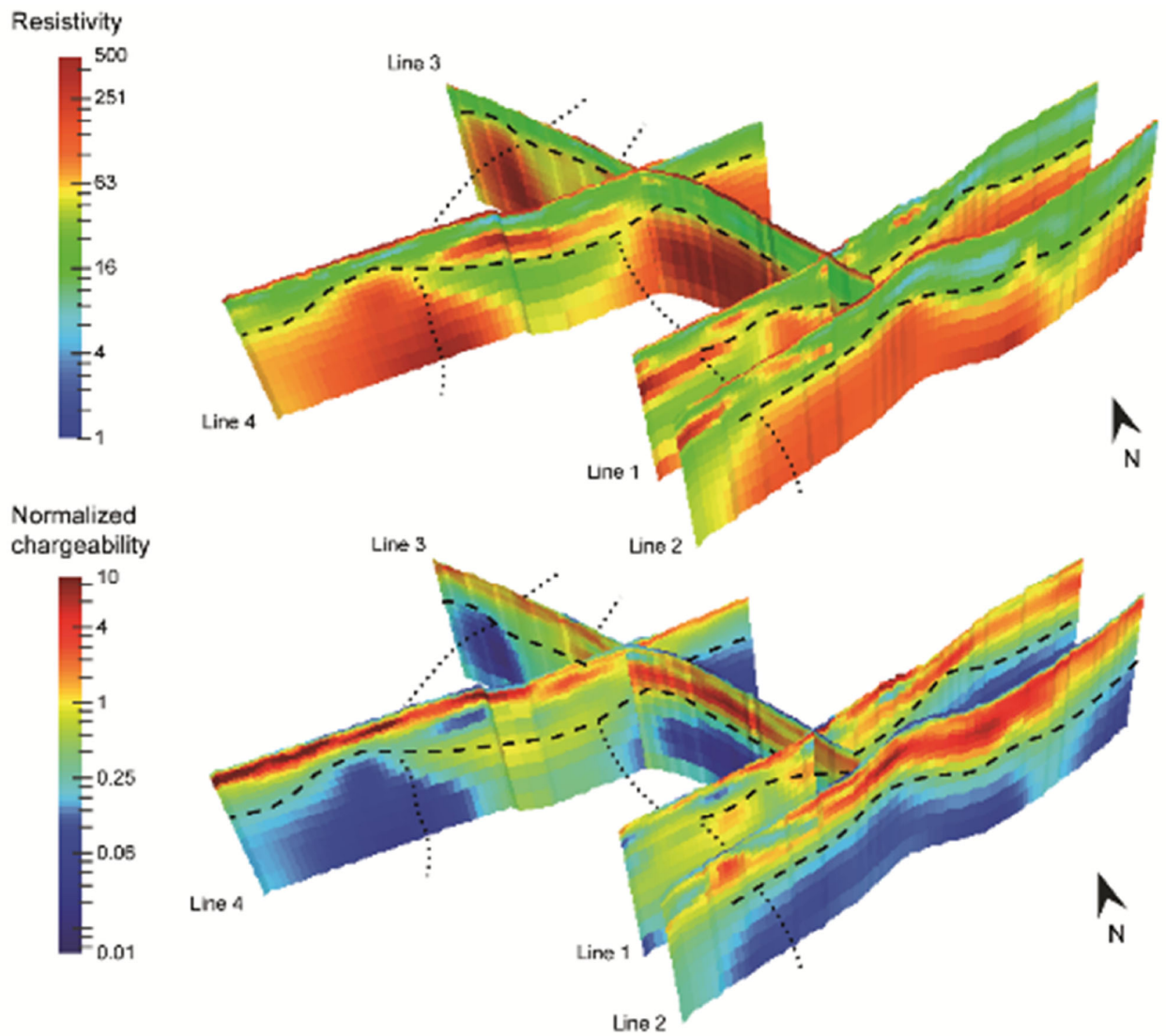

Figure 10. 3D visualization of the resistivity and normalized chargeability results from the main survey area showing a good agreement between the different DCIP profiles. The interpreted bedrock surface is marked with black dashed lines. While the transition to the bedrock is clear in most parts of the site, there are indications of a geological structure with lower resistivity and higher normalized chargeability running through the survey area in a north-south direction.

Table 1. Description of the drill cutting samples and overview of the results from the powder SEM and EDS analysis.

\begin{tabular}{|c|c|c|c|}
\hline Borehole depth (m) & Description & Main elemental constituents & Other elements \\
\hline $186-190$ & Whitegrey chalk, high water content & $\begin{array}{l}\mathrm{Ca}, \mathrm{Si} \text {. Very small amounts of } \mathrm{K}, \mathrm{Al} \\
\text { and } \mathrm{Mg}\end{array}$ & \\
\hline 200-206 & $\begin{array}{l}\text { Browngrey chalk, lumpy with high } \\
\text { water content }\end{array}$ & $\begin{array}{l}\mathrm{Ca}, \mathrm{Si} \text {. Higher proportion of } \mathrm{Si}, \mathrm{K}, \mathrm{Al} \\
\text { and } \mathrm{Mg} \text { compared to the level above }\end{array}$ & $\mathrm{Fe}, \mathrm{S}, \mathrm{Zr}$ \\
\hline 206-210 & $\begin{array}{l}\text { Whitegrey chalk, consolidated with } \\
\text { low water content }\end{array}$ & $\begin{array}{l}\text { Almost pure Ca. Small amounts of } \\
\text { Si. }\end{array}$ & $\mathrm{Fe}, \mathrm{S}$ \\
\hline 211-215 & Greenwhite chalk, high water content & $\begin{array}{l}\mathrm{Ca} \text {, Si. Small amounts of K, } \mathrm{Al} \text { and } \\
\mathrm{Mg} \text {. Similar composition as level } \\
186-190 \mathrm{~m}\end{array}$ & $\mathrm{Fe}, \mathrm{S}, \mathrm{Ti}, \mathrm{Fe}, \mathrm{Cr}, \mathrm{Ni}, \mathrm{W}$ \\
\hline$\sim 235$ & $\begin{array}{l}\text { Green glauconitic sand, high water } \\
\text { content }\end{array}$ & $\begin{array}{l}\text { Si with relatively small amounts of } \\
\mathrm{Ca}, \mathrm{K}, \mathrm{Al} \text { and } \mathrm{Mg} \text {. }\end{array}$ & $\mathrm{Fe}, \mathrm{S}, \mathrm{Ti}$ \\
\hline$\sim 243$ & $\begin{array}{l}\text { Green glauconitic sand, high water } \\
\text { content }\end{array}$ & $\begin{array}{l}\mathrm{Si} \text { with relatively small amounts of } \\
\mathrm{Ca}, \mathrm{K}, \mathrm{Al} \text { and } \mathrm{Mg} \text {. Significant } \\
\text { amounts of } \mathrm{Fe} \text {. }\end{array}$ & $\mathrm{Fe}, \mathrm{S}, \mathrm{Ti}$ \\
\hline$\sim 247$ & $\begin{array}{l}\text { Light green glauconitic sand, high } \\
\text { water content }\end{array}$ & $\begin{array}{l}\mathrm{Si} \text { with relatively small amounts of } \\
\mathrm{Ca}, \mathrm{K}, \mathrm{Al} \text { and } \mathrm{Mg} \text {. Less amount of } \mathrm{Fe} \\
\text { compared to the level above. }\end{array}$ & $\mathrm{Fe}, \mathrm{S}, \mathrm{Cr}, \mathrm{Ni}, \mathrm{Zr}, \mathrm{P}$ \\
\hline
\end{tabular}

SEM and EDS-analysis confirmed the observation that the major part of the thin section consisted of calcium carbonate, although a few silica grains (quartz) were also found in the sample.

Photographs of the thin section from borehole level 211 to $215 \mathrm{~m}$ are shown in Fig. 13. The limestone sample from this borehole level consists mainly of sand-sized carbonate grains (fossil fragments/skeletal grains, relatively well sorted) interspersed by calcite cement, but the structure and composition of the material differs from the borehole level above. The carbonate texture varies between packstone and grainstone (Dunham 1962). The rock sample in the thin section consists of 62 per cent grains, 23 per cent cement and 15 per cent micritic matrix. The grain assemblages contain a larger proportion of relatively well-preserved grains, typically elongate in shape (Fig. 13a). Fossil types include putative bivalves and coralline algae, ostracodes (Fig. 13b) echinoderm debris (Fig. 13c), putative bivalves and coralline algae, and ostracode- 

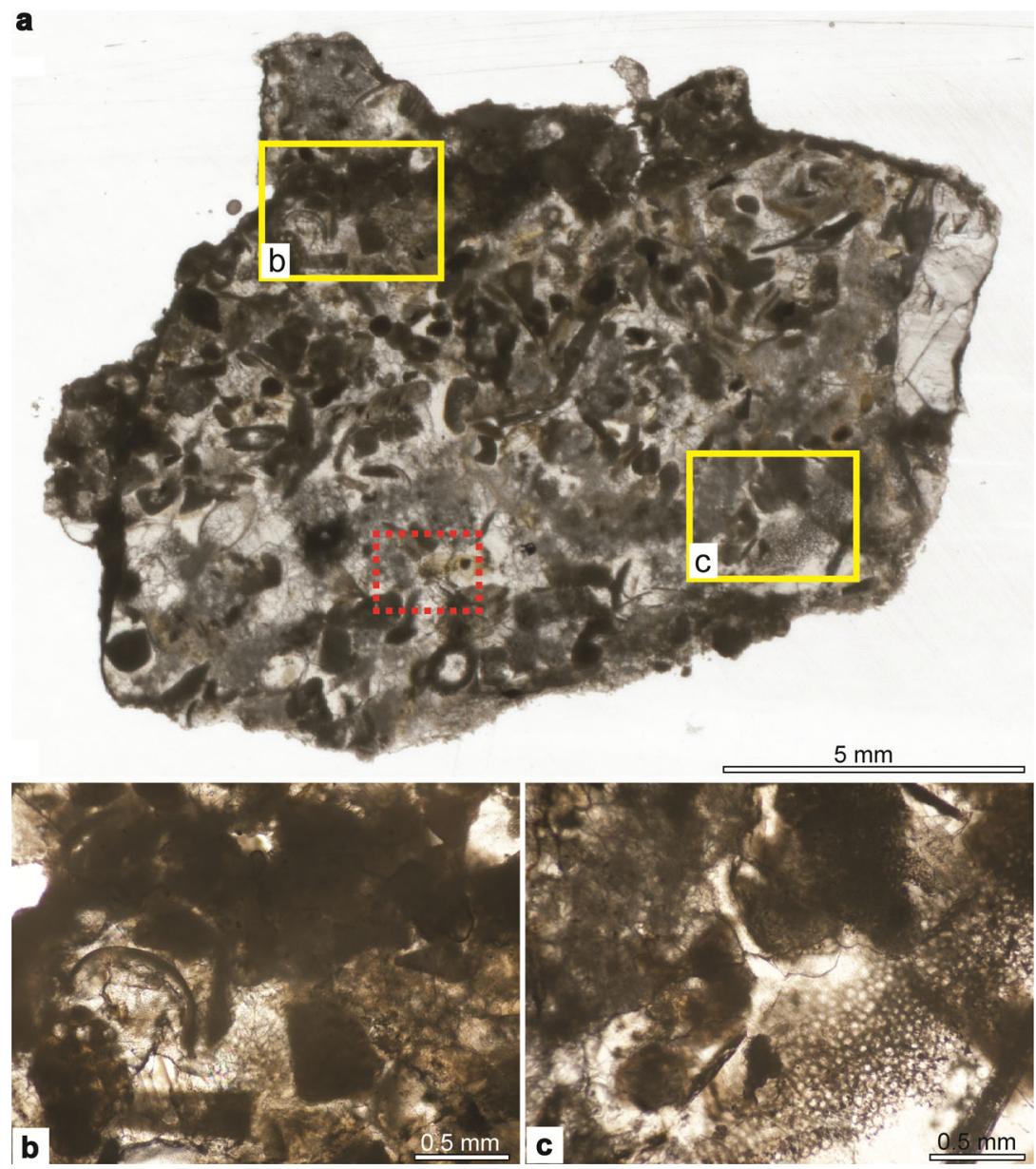

Figure 11. (a) Photograph of the thin section from borehole level 206-211 m (transmitted light). The yellow quadrangles indicate subareas depicted in (b) and (c), and the red dashed quadrangle indicates subarea investigated with SEM and EDS-analysis (Fig. 12). (b) Petrographic microscope images (polarized light) showing details of the carbonate texture, including ostractode valve (middle left) and minute phytodebris ( opaque grains). (c) Fragmented skeletal grains, calcite cement and micrite-like matrix.

like valves. Microbioerosion is extensive and many grains contain numerous minute borings produced by endolithic microorganisms. The carbonate texture varies between packstone and grainstone (Dunham 1962). The calcium carbonate in the thin section consist of 62 per cent grains, 23 per cent cement and 15 per cent micritic matrix.

Also in contrast to the borehole level above, a significantly larger amount of quartz and feldspar grains are found in this sample. Grains of apatite $(\mathrm{Ca}, \mathrm{P})$ and pyrite $(\mathrm{Fe}, \mathrm{S})$ were also identified with the SEM and EDS-analysis, as well as glauconitic grains (Fe, Si), see Figs 14 and 15 . The average proportion of siliciclastic and glauconitic grains in the thin section are 8 and 1.6 per cent, respectively. The chemical mappings from the SEM and EDS-analysis imply a combination of calcite cement and clay matrix surrounding the sand sized grains. The distribution of pyrite and glauconitic grains vary in different subsections, as can be seen in Fig. 15.

Fig. 16 shows the thin section of the glauconitic sandstone sample $(\sim 247 \mathrm{~m})$. The material consists of larger and smaller silicate grains embedded in a finer matrix with a greenish to blackish colour (glauconitic and possibly pyritic substances). The chemical mapping (Fig. 17) shows that the larger grains are mainly composed of quartz and feldspar, although a larger apatitic grain is also visible (indicated by high amounts of $\mathrm{Ca}$ and $\mathrm{P}$ ). Glauconitic grains are indicated by $\mathrm{Fe}$ in combination with $\mathrm{Si}$ or $\mathrm{K}$. $\mathrm{Fe}, \mathrm{Ca}$ and $\mathrm{P}$ generally seem to be present both as small grains and as finer material in between the large silicate grains.

\section{DISCUSSION}

\section{DCIP results}

The urban character of the site and the noise that affected data complicated the data processing, inversion and interpretation in this study. The signal processing scheme successfully reduced periodic noise and allowed retrieval of data from early decay times. Use of early decay times increases the risk of coupling effects in the data superimposed on the information arising from the geological target (Dahlin \& Leroux 2012). However, many of the decays appeared to be unaffected by such effects and all early decay times that were suspected to contain coupling effects were removed from the data set during the processing.

The short current pulses used during the measurements $(1 \mathrm{~s}$ onoff times) can lead to lower signal-to-noise ratio than what would be achievable with longer current pulses (Olsson et al. 2015). Another implication might be a reduction of spectral information in the decays, especially in the case of long relaxation times in the 

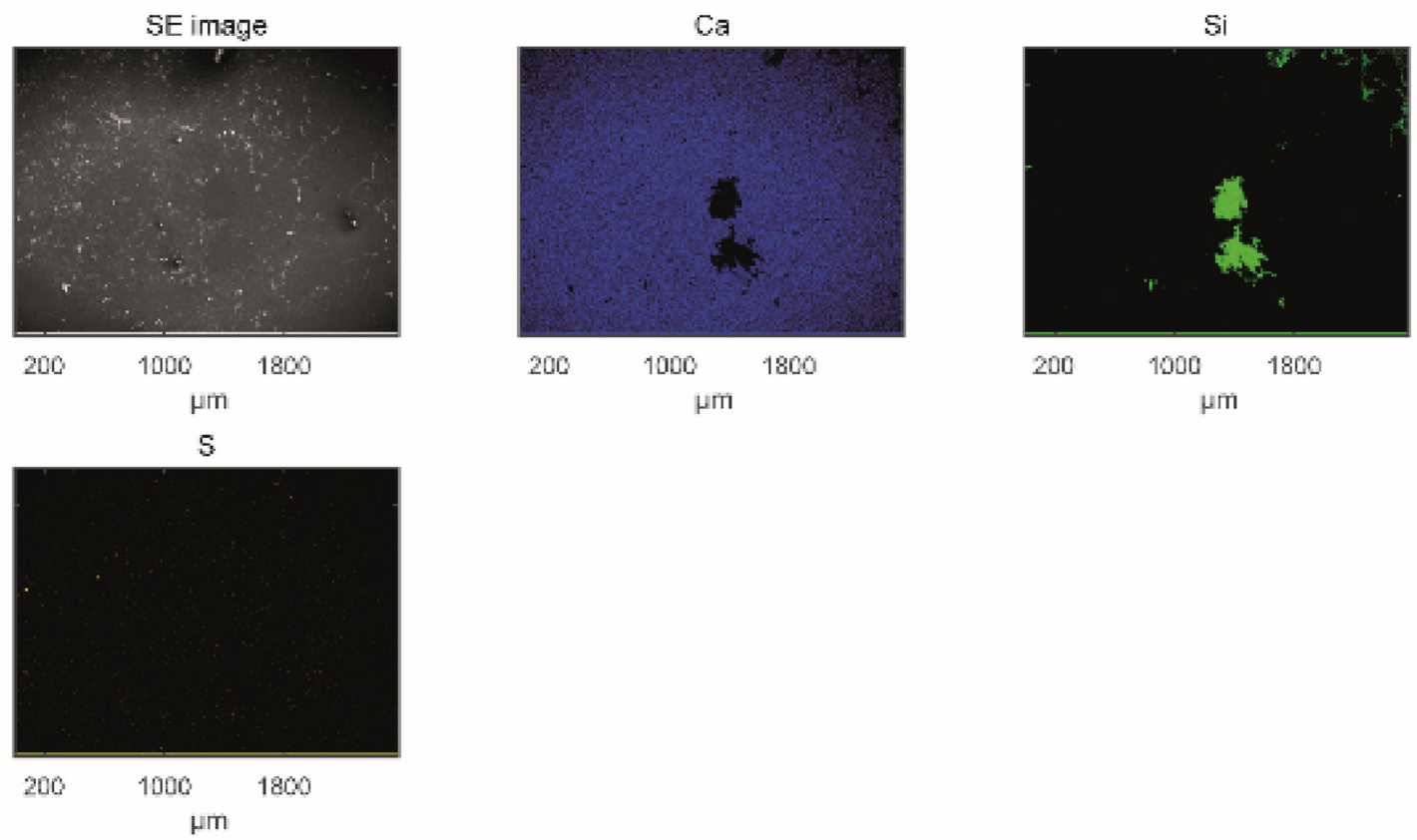

Figure 12. Chemical mapping of the thin section from the 206 to $201 \mathrm{~m}$ level (Fig. 11a). The limestone sample almost exclusively consist of calcium carbonate.
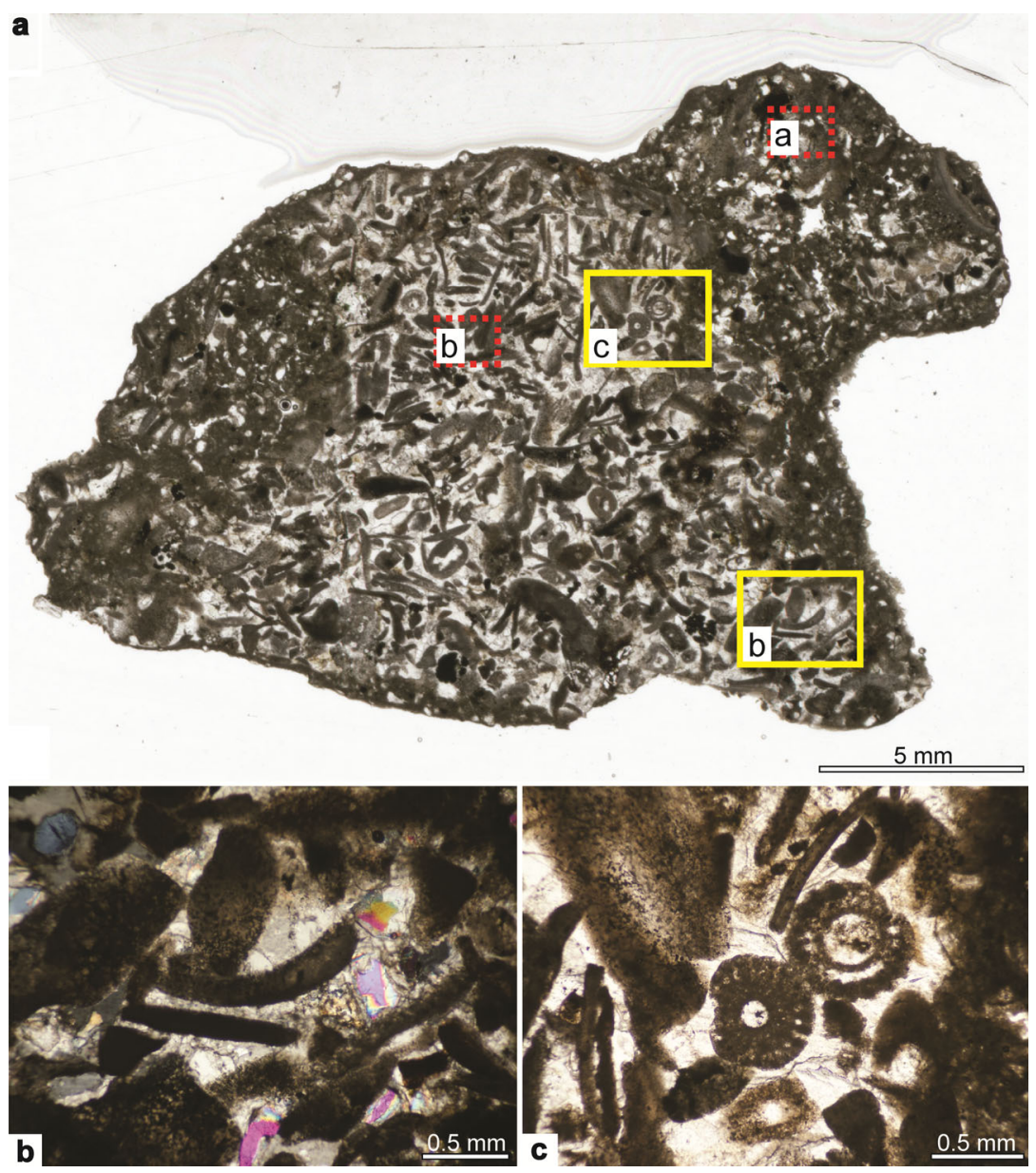

Figure 13. (a) Photograph of the thin section from borehole level 211-216 $\mathrm{m}$ (transmitted light). The yellow quadrangles indicate subareas depicted in (b) and (c), and the red dashed quadrangle indicates subarea investigated with SEM and EDS-analysis (Figs 14 and 15). (b) Petrographic microscope image (polarized light) showing details of the carbonate texture, including mollusc grains, echinoderm debris, and silicate grains (coloured due to the polarized light). (c) Details of the carbonate texture including echinoderm remains. 


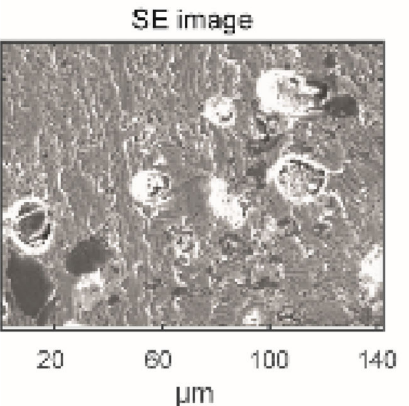

Al

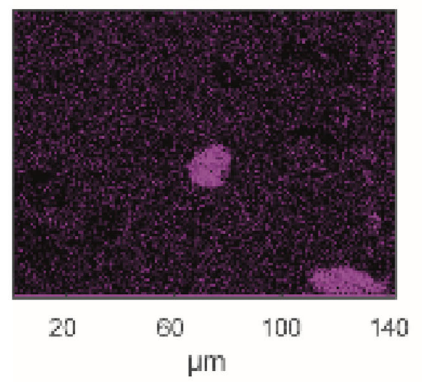

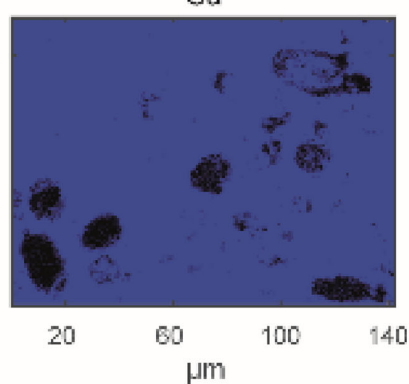

$\mathrm{Fe}$

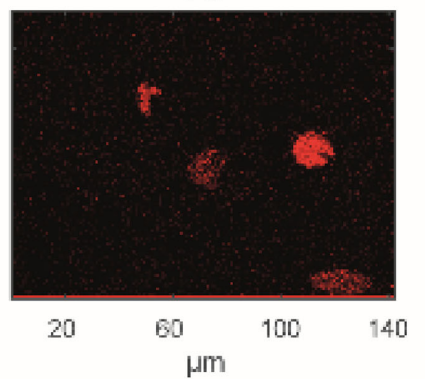

Si

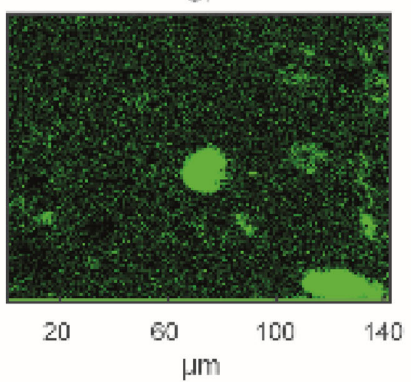

$\mathrm{s}$

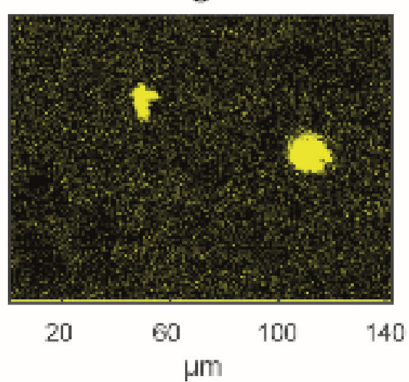

Figure 14. Chemical mapping of thin section from the 211 to $215 \mathrm{~m}$ level (red quadrangle a in Fig. 13a). The chemical mapping indicates pyrite grains (Fe, $\mathrm{S})$ and glauconitic feldspar grains $(\mathrm{Fe}, \mathrm{Al}$ and $\mathrm{Si})$ interspersed in the limestone $(\mathrm{Ca})$.

subsurface. The retrieval of early decay times increased the spectral content of the IP decays in this study, and the Cole-Cole model could be used to fit the data.

The previous difficulties in characterizing the geological setting around the main survey area with drilling methods alone were partially resolved with the inverted results from the DCIP survey. While it was difficult to estimate the transition between the till and the bedrock surface based on drilling data, the resistivity models often show clear transitions between the interpreted low resistivity Quaternary deposits and high resistivity limestone bedrock. In Fig. 10, the interpreted bedrock surface is marked with black dashed lines, and it can be seen that the bedrock level is easily distinguished in the northeastern part of the site. Through the central areas of the site, however, the resistivity results consistently indicate a discontinuation of the bedrock surface forming a geological structure running in an approximately north-south direction.

The modelled resistivity values in the interpreted bedrock varied in both the main and reference survey areas and were generally in the range 100-500 $\Omega \mathrm{m}$. At some locations, the resistivity values also reached well above $500 \Omega \mathrm{m}$ (see Figs 7-9). In the geometrically connected anomaly in the main survey area (Fig. 10), the resistivity values were below $100 \Omega \mathrm{m}$. These values are in the same order of magnitude as the overlying till, but since the normalized chargeability values are elevated, the structure is not interpreted as a depression in the bedrock surface topography (see Johansson et al. 2015 for details on the resistivity and IP responses of the Quaternary deposits in the same survey area).

The low resistivity measured in the anomalous geological structure in the interpreted bedrock indicate either locally higher water conductivity, fractured or porous bedrock with higher water content or a difference in the lithology. Locally elevated water conductivity could be a possible explanation, as the degradation of tetrachloroethylene involves release of chloride ions which may induce changes of the groundwater conductivity. However, chlorinated hydrocarbons are resistive compounds and it is unlikely that the released chloride ions would lead to a strong decrease in resistivity as observed here. Neither is the possible interpretation of locally higher water content supported as the only explanation since the normalized chargeability is elevated in the low resistivity zone; according to previous research, higher water content would more likely lead to decreased normalized chargeability values (see e.g. Titov et al. 2004). That is, with regards to the IP results, it is more likely that low resistivity anomalies in the bedrock are caused by a local variation in the composition or structure of the limestone bedrock. Because of the challenging urban environment in the main survey area, it cannot be excluded that some of the chargeability variations are caused by unidentified buried infrastructures or 3D effects. However, since the reference survey area can be assumed to be free from buried urban infrastructure, the variations in Cole-Cole parameters found in the reference survey area show that natural IP variations within the limestone in the Kristianstad basin are probable. It is possible that the anomalous zone also in the main survey area might arise due to lateral differences in limestone composition or structure. Similar anomalies characterized by high chargeability and low resistivity have in previous research been observed in fractured silicate bedrock, where they were interpreted as a result of clay weathering (Marescot et al. 2008; Magnusson et al. 2010). However, the weathering processes in pure limestone usually results in dissolution of calcium carbonate into the groundwater without any significant precipitation of clay minerals. Other more likely explanations of the observed IP variations were therefore sought for in the properties of the Kristianstad basin limestone.

\section{Microgeometrical variations of the Kristianstad limestone}

Pure limestone is generally expected to produce low polarization effects in the low frequency range, and an absence of IP effects have been observed during laboratory SIP measurements on rock 

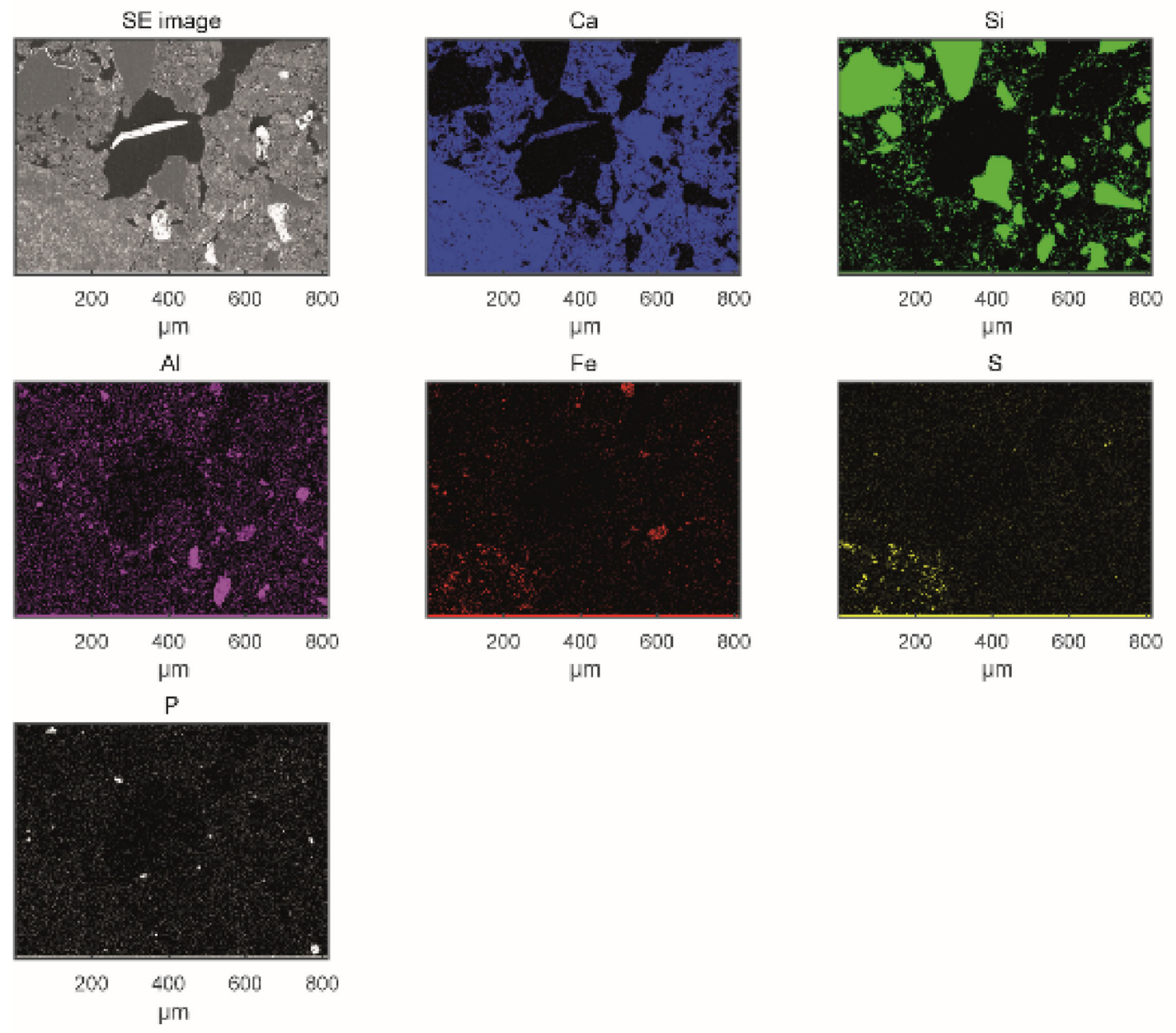

Figure 15. Chemical mapping of thin section from the 211 to $215 \mathrm{~m}$ level (red quadrangle b in Fig. 13a). High concentration of pyrite can be observed in the lower left corner (as indicated by $\mathrm{Fe}$ and $\mathrm{S}$ ). The high and widely distributed $\mathrm{Al}$ and $\mathrm{Si}$ concentrations indicate clay matrix surrounding the grains of calcium carbonate $(\mathrm{Ca})$, quarts $(\mathrm{Si})$, feldspar $(\mathrm{Si}$ and $\mathrm{Al}$ ) and apatite $(\mathrm{Si}$ and $\mathrm{P})$. A few of the grains are probably glauconitic (Fe in combination with $\mathrm{Si}$ and $\mathrm{Al}$ ). The dark parts in the SE image probably represent cavities in the material (or possibly organic carbon).

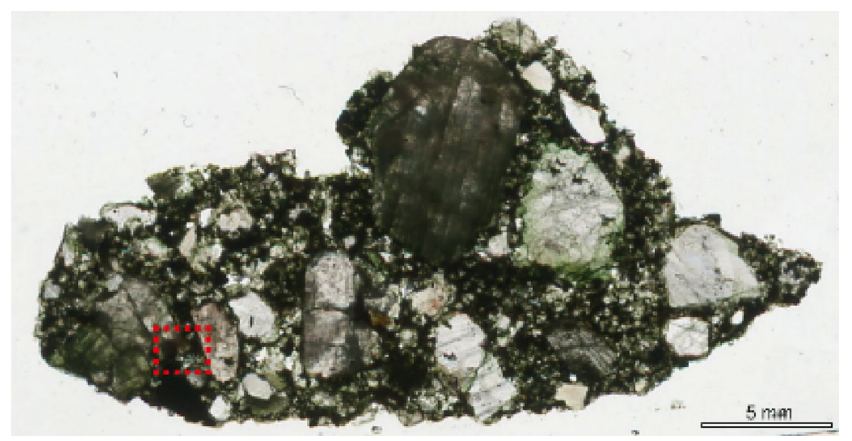

Figure 16. Photograph of the thin section from borehole level $\sim 247 \mathrm{~m}$. The red quadrangle indicates the subarea corresponding to the chemical mapping in Fig. 17.

samples (Ghorbani et al. 2009). The surface charge on calcium carbonate minerals is weaker compared to the surface charge of, for example silica minerals (Zhang et al. 2012) which can explain weak polarization effects caused by the electrochemical mechanism (e.g. Schwarz 1962; Revil \& Florsch 2010). However, since other IP mechanisms are dependent on pore geometry, it could be pos- sible that fossil shapes, limestone texture or changes induced by calcium carbonate dissolution and precipitation processes in the rock could affect both the spectral shapes and the strength of the IP signals. Laboratory studies have shown indications of either increased or decreased polarization responses due to calcium carbonate precipitation in granular media. The precipitated calcium carbonate minerals change microgeometrical properties of the pore space, and the polarization response seem dependent on whether the calcium carbonate precipitates on grain surfaces or as small discrete particles in the pore space (Zhang et al. 2012).

It cannot be excluded that interfacial polarization mechanisms are present in the early decay times of our data which could influence the results. In the higher frequency range of $100 \mathrm{~Hz}-100 \mathrm{kHz}$, variations in the dielectric constant among different limestone and dolomite samples have been measured with dielectric spectroscopy by Sengwa \& Soni (2006). The dielectric constant and its frequency variation was attributed to both electrochemical and interfacial polarization mechanisms, which appeared dependent on the chemical composition, density, porosity, water content and inhomogeneity of the samples (Sengwa \& Soni 2006).

The SEM and EDS-analyses of samples from the Åhus borehole showed that both the structure and the composition of the lime- 

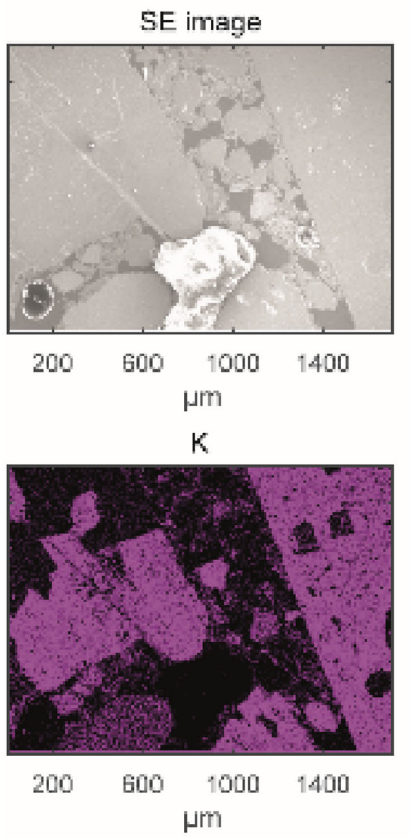

$\mathrm{P}$

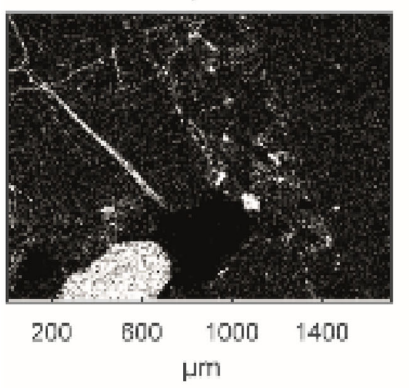

$\mathrm{Ca}$

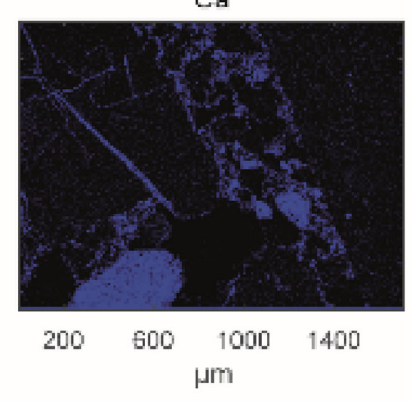

$\mathrm{Fe}$

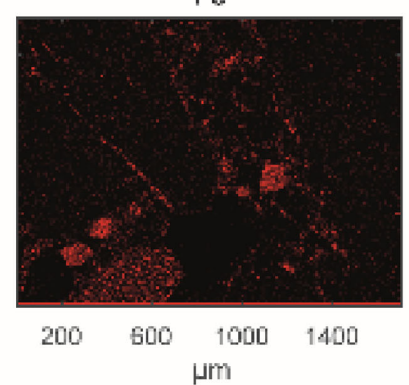

Si

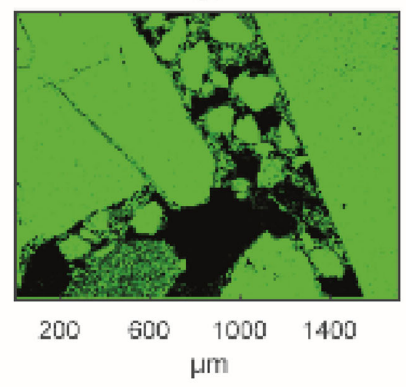

5

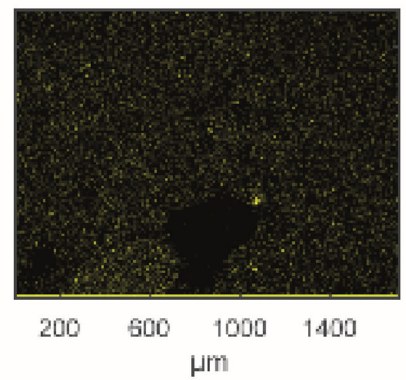

Figure 17. SEM and EDS results in a subarea of the thin section from the glauconitic sand at borehole level $\sim 247 \mathrm{~m}$. The larger grains consist of quartz ( $\mathrm{Si}$ ), feldspar ( $\mathrm{K}$ and $\mathrm{Si}$ ) and apatite $(\mathrm{Ca}$ and $\mathrm{P})$. With the exception of the bottom left grain, apatite and calcium carbonate is mainly distributed in cracks and as finer material between the larger grains. The Fe distribution shows that some of the larger grains are glauconitic and that glauconitic fine-grained material is also present in the sample.

stone varied at different levels in the borehole. While the limestone at level $206-211 \mathrm{~m}$ can be classified as a grainstone, the texture varies more distinctly between packstone and grainstone at level 211-215 m. Varying amounts of argillaceous matrix in the limestone could probably give rise to varying IP responses, as clayey materials are known to display IP effects (see e.g. Slater \& Lesmes 2002a). At the borehole level 206-211 m, the limestone sample was almost exclusively composed of calcium carbonate. In contrast, argillaceous matrix and a significant amount of silicate minerals were indicated at level $211-215 \mathrm{~m}$.

Another possible source of varying IP effects is local presence of pyrite minerals in the limestone, which was confirmed with the SEM and EDS analysis. It has been known for a long time that certain minerals, for example magnetite and many sulphides produce IP effects when they are disseminated in a host rock (e.g. Pelton et al. 1978). These minerals have in common that they are electrically conductive; other minerals containing similar elements do not give rise to IP effects due to their low electrical conductivity (e.g. Bertin \& Loeb 1976). Varying heavy mineral occurrence has previously been observed in the Härlöv core, but details about the composition of different types of heavy minerals were not reported by Kornfält et al. (1978). The SEM and EDS analysis of samples from the Århus borehole showed that varying amounts of iron and sulphide were found in most of the investigated borehole levels. Presence of pyrite (or possibly pyrrohotite, both conductive minerals) was confirmed in the limestone at borehole levels between 200 and $215 \mathrm{~m}$ and in the glauconitic sandstone at levels $\sim 243 \mathrm{~m}$ and $\sim 247 \mathrm{~m}$. The chemical mapping of the thin section from 211 to $215 \mathrm{~m}$ indicated relatively high concentrations of pyrite in some subareas (Figs 14 and 15). Pyrite mineral impurities in calcium carbonate have resulted in measureable IP anomalies in previous research. In a study by Okay et al. (2013), calcite-filled cracks in a clay rock formation with 16 per cent (by weight) pyrite gave rise to IP anomalies larger than $10-20 \mathrm{mV} / \mathrm{V}$. In the same formation, calcareous nodules with 5-6 per cent pyrite also produced IP effects of almost the same order of magnitude $(\sim 10-20 \mathrm{mV} / \mathrm{V})$. Even smaller amounts of sulphides can give significant IP responses. Chargeability values of $100-500 \mathrm{mV} / \mathrm{V}$ corresponding to $0.2-2$ per cent disseminated sulphides in porphyry were reported by Pelton et al. (1978).

The detected iron in the Åhus samples was not only present as pyrite. High $\mathrm{Fe}$ concentrations corresponding to the locations of silicates indicated presence of glauconitic grains in the limestone at level 211-215 m (see e.g. Fig. 14). Similar properties may be found at shallower depths in the main survey area, since the transition be- 
tween the limestone and the glauconitic sandstone probably occurs between 50 and $100 \mathrm{~m}$ depth there. Glauconite is an iron-rich micaceous clay mineral (iron potassium phyllosilicate), but glauconite is also used as a general term for greenish sand sized grains in which other mineral types may also be present. In glauconite sand, the mineral glauconite occurs as, for example, pellets (aggregates) or a pigment in cracks and on surfaces of other minerals (McRae 1972). In the glauconite sample investigated here, the glauconite appeared to be present both as pellets/grains, and as fine material on grain surfaces as well as in cracks in between larger quartz and feldspar grains (Fig. 17).

Glauconite usually contain around $15-30$ per cent iron, and although most of the iron is in the ferric state $\mathrm{Fe}_{2} \mathrm{O}_{3}$, glauconite also contain iron in the ferrous state FeO (Carroll 1958; McRae 1972; Thompson \& Hower 1975). The amount of ferrous iron in relation to the total iron content in glauconite is usually in the range 10-20 per cent, but the ratio is also dependent on the redox conditions (McRae 1972; Fanning 1989). Iron oxides in the ferrous state (magnetite and wüstite) have high conductivity and can thus produce high IP effects (Bertin \& Loeb 1976), while iron oxides in the ferric (oxidized) state (hematite) have lower conductivity values (Tannhauser 1962; Vella \& Emerson 2012). It is known from the Härlöv core that glauconitic sand is present at different levels throughout the limestone. It is likely that high presence of glauconite can lead to enhanced IP effects, either due to high conductivity of the iron oxides or due to high cation exchange capacity of the phyllosilicate sheets.

\section{Geological processes}

Microgeometrical structure and mineral content in the bedrock are important factors governing the spectral information in the measured IP signals (see e.g. Pelton et al. 1978; Kemna et al. 2012). Different geological limestone processes leading to large scale vertical or horizontal differences in the microgeometrical properties of limestones can be proposed.

In the Härlöv core, there are variations in the microgeometrical characteristics of the limestone originating from variations in the depositional environment during the formation of the limestone (Fig. 2). If a local depression in the seafloor has been present at some point, it is reasonable that a deeper depositional environment would exist in the depression while shallower conditions prevail in the surroundings. With a local deep sedimentary environment, deposition of smaller grain sizes and larger amounts of muddy matrix are probable.

Local depressions in the limestone bedrock surface could be the result of depressions or weakness zones in the underlying granite bedrock, leading to differences in the sedimentation history of the limestone. It is known that in the Kristianstad area, the grain sizes and constituents of the sandy limestones and calcareous sandstones vary dramatically in both horizontal and vertical directions. These differences have arisen due to a varying depositional environment, with both shallower and deeper marine periods and periods of subaerial exposure (e.g. Christensen 1984).

Another possible cause of local limestone variations is calcium carbonate dissolution and karst formation at some point in time. When karst cavities collapse, they can be filled with surrounding soil or with limestone material from a higher level. Low resistive zones corresponding to clay-filled karst cavities in a limestone formation have been detected in previous research (Park et al. 2014).
Although the limestone in the Kristianstad basin is generally estimated to contain 70-80 per cent calcium carbonate (Kornfält et al. 1978), and even higher proportions were indicated by the thin section analyses in this study, it is still possible that clay weathering of the silicate grains within the limestone occur. However, if weathering in fracture zones occurred in this limestone, it is likely that the increased chargeability would be cancelled out by the increased porosity due to the calcium carbonate dissolution in the fractures.

\section{CONCLUSIONS}

Discrimination between the sandy chalk till and the consolidated limestone had previously been difficult to establish using only drilling in the main survey area. Our results show that the DCIP survey provides an effective imaging of the upper surface of the Cretaceous limestone here.

The normalized chargeability responses of the limestone are low in the major part of the bedrock. However, zones of elevated normalized chargeability are also present. The main survey was performed in a technically challenging urban area, whereas a reference survey performed in a rural area confirmed the presence of natural IP variations within the limestone bedrock. In the reference line, interesting variations in Cole-Cole relaxation time and frequency factor were resolved that probably could reflect textural variations within the limestone.

The microscope and SEM and EDS-analyses of limestone samples from the Kristianstad basin confirmed variations both in terms of structure and of chemical composition at different levels in the borehole. It was suggested that varying amounts of fine-grained matrix, pyrite and glauconitic minerals within the limestone could provide an explanation to the observed variations in chargeability. Varying textural properties, such as for example fossil shapes and composition and the proportion of calcite cement and micritic matrix might induce variations in Cole-Cole relaxation time and frequency factor. However, more research is needed in order to better connect spectral IP responses to different microstructural properties of limestone.

The observed low resistivity and high normalized chargeability anomalies in the main survey area do not specifically indicate zones of higher water conductivity. The dissolution of calcium carbonate in weathered limestone zones would more likely result in low resistive anomalies without any enhanced chargeability. Therefore, we conclude that the anomalous structure more likely originate in a local variation in limestone structure or composition. Vertical variations in microgeometrical properties within a limestone could appear due to local depressions in the Precambrian rock surface, collapsed karst structures or other morphological processes. More research is needed to confirm this interpretation.

The results from this study show that it is possible to recover useable spectral information from early decay times. We also show that under certain conditions (e.g. relatively short relaxation times in the subsurface), it is possible to extract spectral information from time domain IP data measured with as short on-off times as $1 \mathrm{~s}$. Short on-off times significantly reduce the survey time, but longer on-off times are generally recommended if it longer relaxation times can be suspected in the subsurface.

\section{ACKNOWLEDGEMENTS}

We would like to thank Johan Lindgren and Leif Johansson at Department of Geology at Lund University for help, assistance and 
guiding of SEM and thin section preparation, Martin Ekvy at Malmberg Borrning AB for providing drill samples from Åhus and Mikael Lumentzberger and Carl-Henrik Månsson for field work assistance. We are grateful to the two reviewers helping us to improve this paper. Funding for the work was provided by Formas - The Swedish Research Council for Environment, Agricultural Sciences and Spatial Planning (ref. 2012-1931), BeFo - Swedish Rock Engineering Research Foundation (ref. 331), SBUF - The Development Fund of the Swedish Construction Industry (ref. 12719) and Sven Tyréns Stiftelse. The project is part of the Geoinfra-TRUST framework (Transparent Underground Structure, http://trust-geoinfra.se/).

\section{REFERENCES}

Adams, A.E., MacKenzie, W.S. \& Guilford, C., 1984. Atlas of Sedimentary Rocks Under the Microscope, Longman Group Limited.

Auken, E., Viezzoli, A. \& Christiansen, A.V., 2009. A singlesoftware for processing, inverting, and presentation of AEM data of different system: the Aarhus Workbench, in Proceedings of the Australian Society of Exploration Geophysics Geophysicist (ASEG) 2009, Sydney, Australia, Expanded Abstract, 1-5.

Auken, E. et al., 2014. An overview of a highly versatile forward and stable inverse algorithm for airborne, ground-based and borehole electromagnetic and electric data, Explor. Geophys., 46(3), 223-235.

Bertin, J. \& Loeb, J., 1976. Experimental and Theoretical Aspects of Induced Polarization, Gebrüder Borntraeger.

Binley, A., Slater, L.D., Fukes, M. \& Cassiani, G., 2005. Relationship between spectral induced polarization and hydraulic properties of saturated and unsaturated sandstone, Water Resour. Res., 41(12), W12417, doi:10.1029/2005WR004202.

Carroll, D., 1958. Role of clay minerals in the transportation of iron, Geochim. Cosmochim. Acta, 14, 1-28.

Cavinato, G.P., Di Luzio, E., Moscatelli, M., Vallone, R., Averardi, M., Valente, A. \& Papale, S., 2006. The new Col di Tenda tunnel between Italy and France: integrated geological investigations and geophysical prospections for preliminary studies on the Italian side, Eng. Geol., 88(1), 90-109.

Christensen, W.K., 1984. The albian to maastrichtian of Southern Sweden and Bornholm, Denmark: a review, Cretatceous Res., 5, 313-327.

Dahlin, T. \& Leroux, V., 2012. Improvement in time-domain induced polarization data quality with multi-electrode systems by separating current and potential cables, Near Surf. Geophys., 10, 545-565.

Dahlin, T. \& Zhou, B., 2004. A numerical comparison of 2D resistivity imaging with 10 electrode arrays, Geophys. Prospect., 52(5), 379-398.

Dahlin, T., Wisén, R. \& Zhang, D., 2007. 3D effects on 2D resistivity imaging - modelling and field surveying results, in Proceedings of the Near Surface Geoscience 2007, 13th European Meeting of Environmental and Engineering Geophysics, Istanbul, Turkey.

Danielsen, B.E. \& Dahlin, T., 2009. Comparison of geoelectrical imaging and tunnel documentation at the Hallandsås Tunnel, Sweden, Eng. Geol., 107(3-4), 118-129.

Dunham, R.J., 1962. Classification of carbonate rocks according to texture, Classif. Carbonate Rocks, 1, 108-121.

Fanning, D.S., 1989. Oxidation state of iron in glauconite from oxidized and reduced zones of soil-geologic columns, Clay. Clay Miner, 37(1), 59-64.

Fiandaca, G., Auken, E., Christiansen, A.V. \& Gazoty, A., 2012. Timedomain-induced polarization: full-decay forward modeling and 1D laterally constrained inversion of Cole-Cole parameters, Geophysics, 77(3), E213-E225.

Fiandaca, G.,Ramm, J., Binley, A., Gazoty, A., Christiansen, A.V. \& Auken, E., 2013. Resolving spectral information from time domain induced polarization data through 2-D inversion, Geophys. J. Int., 192(2), 631-646.

Fiandaca, G., Ramm, J., Binley, A., Gazoty, A., Christiansen, A.V. \& Auken, E., 2015. Depth of investigation for multi-parameters inversions, in Pro- ceedings of the Near Surface Geoscience 2015, 21st European Meeting of Environmental and Engineering Geophysics, Turin, Italy.

Friel, J.J., 2003. X-Ray and Image Analysis in Electron Microscopy, Princeton Gamma-Tech, 95 pp.

Ganerød, G.V., Rønning, J.S., Dalsegg, E., Elvebakk, H., Holmøy, K., Nilsen, B. \& Braathen, A., 2006. Comparison of geophysical methods for sub-surface mapping of faults and fracture zones in a section of the Viggja road tunnel, Norway, Bull. Eng. Geol. Environ., 65(3), 231-243.

Gazoty, A., Fiandaca, G., Pedersen, J., Auken, E. \& Christiansen, A.V., 2013. Data repeatability and acquisition techniques for time-domain spectral induced polarization, Near Surf. Geophys., 11, 391-406.

Gélis, C., Revil, a., Cushing, M.E., Jougnot, D., Lemeille, F., Cabrera, J., De Hoyos, A. \& Rocher, M., 2010. Potential of electrical resistivity tomography to detect fault zones in limestone and argillaceous formations in the experimental platform of Tournemire, France, Pure appl. Geophys., 167(11), 1405-1418.

Ghorbani, A., Cosenza, P., Revil, a., Zamora, M., Schmutz, M., Florsch, N. \& Jougnot, D., 2009. Non-invasive monitoring of water content and textural changes in clay-rocks using spectral induced polarization: a laboratory investigation, Appl. Clay Sci., 43(3-4), 493-502.

Houssaye, A., Lindgren, J., Pellegrini, R., Lee, A.H., Germain, D. \& Polcyn, M.J., 2013. Microanatomical and histological features in the long bones of mosasaurine mosasaurs (reptilia, squamata) - implications for aquatic adaptation and growth rates, PLoS ONE, 8(10), $1-12$.

Ingeman-Nielsen, T., Tomaškoviová, S. \& Dahlin, T., 2016. Effect of electrode shape on grounding resistances-Part 1: The focus-one protocol, Geophysics, 81(1), WA159-WA167.

Johansson, S., Fiandaca, G. \& Dahlin, T., 2015. Influence of non-aqueous phase liquid configuration on induced polarization parameters: conceptual models applied to a time-domain field case study, J. appl. Geophys., 123, 295-309.

Kemna, A. et al., 2012. An overview of the spectral induced polarization method for near-surface applications, 2012. An overview of the spectral induced polarization method for near-surface applications, Near Surf. Geophys., 10, 453-468.

Kornfält, K.-A., Bergström, J., Carserud, L., Henkel, H. \& Sundquist, B., 1978. Description to the map of solid rocks and the aeromagnetic map Kristianstad SO, Swedish Geological Survey.

Magnusson, M.K., Fernlund, J.M.R. \& Dahlin, T., 2010. Geoelectrical imaging in the interpretation of geological conditions affecting quarry operations, Bull. Eng. Geol. Environ., 69(3), 465-486.

Marescot, L., Monnet, R. \& Chapellier, D., 2008. Resistivity and induced polarization surveys for slope instability studies in the Swiss Alps, Eng. Geol., 98(1-2), 18-28.

McRae, S.G., 1972. Glauconite, Earth-Sci. Rev, 8(4), 397-440.

Okay, G., Cosenza, P., Ghorbani, A., Camerlynck, C., Cabrera, J., Florsch, N. \& Revil, A., 2013. Localization and characterization of cracks in clayrocks using frequency and time-domain induced polarization, Geophys. Prospect., 61(1), 134-152.

Olsson, P.I., Fiandaca, G., Dahlin, T. \& Auken, E., 2015. Impact of time-domain IP pulse length on measured data and inverted models, in Proceedings of the Near Surface Geoscience 2015, 21st European Meeting of Environmental and Engineering Geophysics, Turin, Italy.

Olsson, P.-I., Fiandaca, G., Larsen, J.J., Dahlin, T. \& Auken, E. (2016). Doubling the spectrum of time-domain induced polarization by harmonic de-noising, drift correction, spike removal, tapered gating and data uncertainty estimation, Geophys. J. Int., 207(2), 774-784.

Park, M.K., Park, S., Yi, M.J., Kim, C., Son, J.S., Kim, J.H. \& Abraham, A.A., 2014. Application of electrical resistivity tomography (ERT) technique to detect underground cavities in a karst area of South Korea, Environ. Earth Sci., 71, 2797-2806.

Pelton, W.H., Ward, S.H., Hallof, P.G., Sill, W.R. \& Nelson, P.H., 1978. Mineral discrimination and removal of inductive coupling with multifrequency IP, Geophysics, 43(3), 588-609. 
Revil, A. \& Florsch, N., 2010. Determination of permeability from spectral induced polarization in granular media, Geophys. J. Int., 181(3), 14801498.

Schwarz, G., 1962. A theory of the low-frequency dielectric dispersion of colloidal particles in electrolyte solution, J. Phys. Chem., 66(12), 26362642.

Scott, J.B.T. \& Barker, R.D., 2003. Determining pore-throat size in PermoTriassic sandstones from low-frequency electrical spectroscopy, Geophys. Res. Lett., 30(9), 1450, doi:10.1029/2003GL016951.

Sengwa, R.J. \& Soni, A., 2006. Low-frequency dielectric dispersion and microwave dielectric properties of dry and watersaturated limestones of the Jodhpur region, Geophysics, 71(5), G269-G277.

Slater, L. \& Lesmes, D.P., 2002a. Electrical-hydraulic relationships observed for unconsolidated sediments, Water Resour. Res., 38(10), $1-13$.

Slater, L.D. \& Lesmes, D., 2002b. IP interpretation in environmental investigations, Geophysics, 67(1), 77-88.

Sumner, J.S., 1976. Principles of Induced Polarization for Geophysical Exploration, Elsevier Scientific Publishing Company.
Tannhauser, D.S., 1962. Conductivity in iron oxides, J. Phys. Chem. Solids, 23(1-2), 25-34.

Thompson, G.R. \& Hower, J., 1975. The mineralogy of glauconite, Clay. Clay Miner, 23(4), 289-300.

Titov, K., Kemna, A., Tarasov, A. \& Vereecken, H., 2004. Induced polarization of unsaturated sands determined through time domain measurements, Vadose Zone J., 3(4), 1160-1168.

Tucker, M.E. \& Wright, V.P., 1990. Carbonate Sedimentology, Blackwell Science, $482 \mathrm{pp}$.

Vella, L. \& Emerson, D., 2012. Electrical properties of magnetite- and hematite-rich rocks and ores, in Proceedings of the 22nd ASEG Conference \& Exhibition, pp. 1-4.

Ward, S.H., 1990. Resistivity and induced polarization methods, in Investigations in Geophysics no. 5: Geotechnical and Environmental Geophysics, Vol. I, pp. 147-189, ed. Ward, S., Society of Exploration Geophysicists.

Zhang, C., Slater, L., Redden, G., Fujita, Y., Johnson, T. \& Fox, D., 2012. Spectral induced polarization signatures of hydroxide adsorption and mineral precipitation in porous media, Environ. Sci. Technol., 46(8), 43574364. 